SREL - 49

$\mathrm{UC}-66 \mathrm{e}$

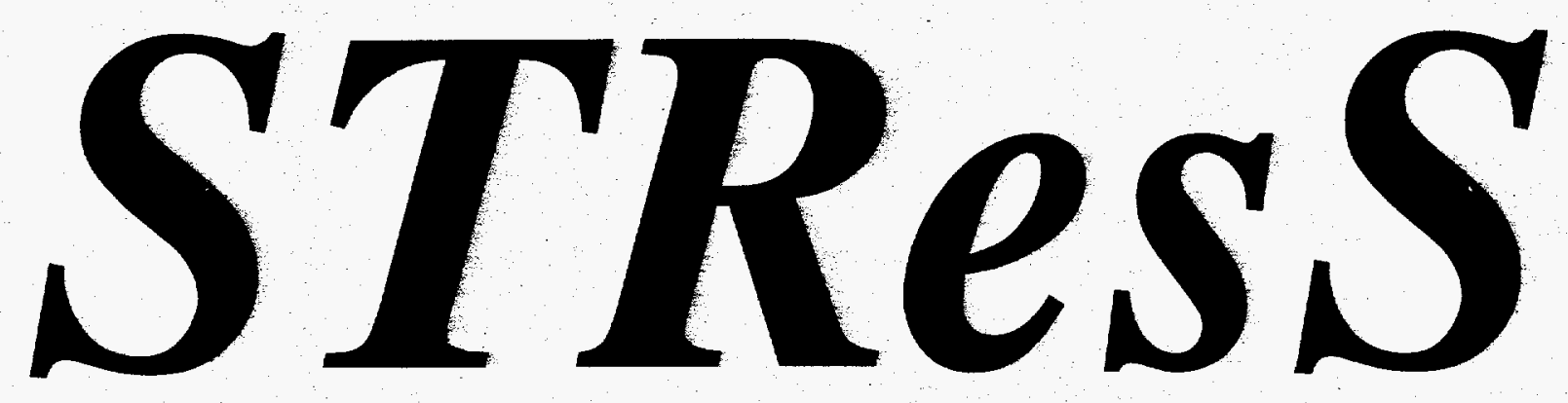

\title{
(Simulated Toxicant-Related Stress) Documentation
}

K.D. Greene, M.C. Newman, and R.H. Jagoe

\author{
University of Georgia \\ Savannah River Ecology Laboratory \\ Drawer $E$ \\ Aiken, SC 29801 \\ DISCLAIMER
}

望

This report was prepared as an account of work sponsored by an agency of the United States Government. Neither the United States Government nor any agency thereof, nor any of their employees, makes any warranty, express or implied, or assumes any legal liability or responsibility for the accuracy, completeness, or usefulness of any information, apparatus, product, or process disclosed, or represents that its use would not infringe privately owned rights. Reference herein to any specific commercial product, process, or service by trade name, trademark, manufacturer, or otherwise does not necessarily constitute or imply its endorsement, recommendation, or favoring by the United States Government or any agency thereof. The views and opinions of authors expressed herein do not necessarily state or reflect those of the 


\section{DISCLAIMER}

Portions of this document may be illegible in electronic image products. Images are produced from the best available original document. 


\section{INTRODUCTION}

STResS (Simulated Toxicant-Related Stress) is a program written in DEC FORTRAN v. 6.2. This program can be run either interactively or batch mode. This program is designed to model the effects of toxicant exposure on a simulated population of a specific species, as well as the effects of the toxicant on the demographic and genetic characteristics. The toxic effect on the time-to-death is based on an accelerated failure time model in which the time-to-death depends on size, sex and genotype, toxicant concentration, and frequency and duration of exposure. Sexual, fecundity, and meiotic drive/gametic selection can also be included. Multiple simulations can be run for a user-specified number of gestation periods of user-specified length. The effect of winter can be included, and the exposure duration can be changed once during each simulation, if desired. 


\section{INSTRUCTIONS}

To run STResS in interactive mode, type RUN STRESS at the prompt. Following the instructions given on the screen, enter the information requested. Data can be entered completely interactively or via a previously entered data file. A previously entered data file can be modified interactively and corrections to a data file can be identified and corrected interactively. (An incorrect data type will cause a fatal error.) Once all the information requested is entered correctly, the simulations will begin running. In interactive mode, the simulations, gestation periods, populations, and median time-to-death are written to the screen as the simulations progress. The program can be terminated at any time by typing [ctrl]Y to interrupt. All outputs are written at the user's request.

To run STResS in batch mode, type SUBMIT STRS at the prompt. The data file must be complete and correct or the program will terminate with errors. If a file is not already created, one can be created by running STResS in interactive mode, saving, interrupting the program, and running Make.exe (type RUN MAKE). However, it is only necessary to run Make if a data file exists for the interactive mode. Following the instructions given on the screen, enter the information requested. Data must be entered via a previously entered data file with the filename STRS.DAT. 
STResS is a FORTRAN program designed to model the effects of toxicant exposure on a population of fish. The program can be used to find the effect of the toxicant on the demographic and genetic characteristics of a simulated population. This model incorporates population dynamics specific to mosquitofish (Gambusia holbrooki) but could be adapted to describe other species. The toxic effect on the time-to-death is based on an accelerated failure time model in which the time-to-death depends on size, sex and genotype, toxicant concentration, and frequency and duration of exposure. Sexual, fecundity, and meiotic drive/gametic selection can also be included. Multiple simulations can be run for a user-specified number of gestation periods of user-specified length. The effect of winter can be included, and the exposure duration can be changed once during each simulation, if desired.

At the beginning of the program, the data are entered with the aid of the DATA_ENTRY module. Counter values are initialized and the maximum population size is set. Next an initial population is generated and the simulation loop is started. The number of males and females in the initial population depends on the user specified sex ratio, and whether the user has designated the reference sex as male or female. The subroutine CREATE assigns characteristics to the initial population. FISH is a two dimensional array, the first element containing ID numbers to identify the individual fish, and the second element containing the eight fish characteristics:

1. $\operatorname{sex}$

2. size (wet weight in milligrams)

3. cumulative survival

4. median time-to-death due to toxicant exposure

5. age

6. natural time-to-death

7. growth rate

8. winter time-to-death

CREATE employs several subroutines. Among these are:

ASSIGNSEX, which randomly assigns a sex to each fish according to the user-specified sex ratio.

WEIGHTS randomly assigns a size to each fish. The user specifies the type of underlying distribution assumed (normal or lognormal), and separate mean weights and standard deviations for males and females.

GROWTH assigns an initial age to each individual in the population. The individual fish's sizes (assigned above) are compared to sizes calculated from the logistic equation (Philippi et al., 1987) in order to determine the individual's age.

$$
W_{t=1}=w_{t}\left[1+r\left(1-\left(\frac{W_{t}}{W_{\max }}\right) \quad\right]\right.
$$

\footnotetext{
where $\mathrm{t}=$ timestep (each representing a gestation period of 28 days for mosquitofish)

$\mathrm{W}_{\mathrm{t}}=\quad$ the individual's weight at the current timestep
} 


$$
\begin{aligned}
& W_{t+1}=\text { the weight at the next timestep } \\
& W_{\max }=\text { the user specified maximum allowed weight (different for males and females) } \\
& r \quad=\quad \text { the growth rate assigned by CREATE (different for males and females) } \\
& \text { SHAPE }=\text { the user specified shape parameter. }
\end{aligned}
$$

NANDW assigns a time-to-death for each fish based on winter or other natural causes. The equation below (Kennedy and Gentle, 1980) is used to generate a random time-to-death from a Weibull distribution:

$$
\text { NATTTD }=\operatorname{SCALE}[-\ln (1-z)]^{\nu / \beta}
$$

where $\mathrm{z}$ is a random number from a normal distribution, and SCALE and $\beta$ are user-specified scale and shape parameters There are separate parameters for males and females, and for winter and non-winter.

GROWTHRATE assigns a random growth rate to each fish. The growth rates are assumed to be normally distributed, with separate user-specified means and standard deviations for males and females.

GETGENO assigns genotypes according to user-specified frequencies.

CREATE is also called every time step to assign characteristics to newborn fish and to immigrant fish if applicable.

The subroutine CALC calculates the cumulative survival and median time-to-death of each fish due to toxicant exposure. The approach is based on an accelerated failure time model (Dixon and Newman, 1991, Newman and Aplin, 1992), where the time-to-death due to toxicant exposure is

$$
\begin{aligned}
\log \text { TTD } & =\mu+X \cdot \beta+\sigma * \epsilon \\
\text { TTD } & =\exp (\mu+X \cdot \beta+\sigma * \epsilon) \\
& =\exp (\mu+X \cdot \beta) \exp (\sigma * \epsilon)
\end{aligned}
$$

where: $\mu=$ intercept

$X=$ the matrix of covariates (e.g., sex, weight, genotype)

$\beta=\quad$ vector of parameters that indicate the effect of $X$ on the hazard (e.g., $\beta_{s}, \beta_{w}, \beta_{g}$ ). This is not the same as the $\beta$ which occurs in Equation 2.

$\sigma=\quad$ scale factor

$\epsilon=$ the assumed error distribution (e.g., normal, exponential, Weibull, log normal, etc.).

The median time-to-death is then 


$$
\text { MTTD }=\exp (\mu+X \cdot \beta) \exp \left(\sigma * \epsilon_{0.50}\right)
$$

where $\epsilon_{0.50}$ denotes the 50 th percentile of the error distribution. For example, for the Weibull distribution, $\epsilon_{0.50}=$ -0.3665 .

The equation for cumulative mortality depends on the assumed error distribution. For the Weibull distribution, the cumulative mortality is (Pinder, et al., 1978)

$$
\text { CUMMORT }=\exp \left(-\alpha t^{\gamma}\right)
$$

$$
\begin{aligned}
& \text { Where } \gamma=1 / \sigma \\
& \begin{aligned}
\alpha & =\left[\exp \left(-\mu+\operatorname{sex}^{*} \beta_{\mathrm{s}}+\text { weight }{ }^{*} \beta_{\mathrm{w}}+\text { genotype* } \beta_{\mathrm{g}}\right)\right] / \sigma \\
\mathrm{t} & =\text { duration of exposure (can be changed once during each simulation, if desired) }
\end{aligned}
\end{aligned}
$$

The fish weights in Equation 5 are assumed to be either normally or log normally distributed. $\beta_{w}$ will differ for these two cases. The cumulative survival is

$$
\text { CUMSURV }=1-\text { CUMMORT }
$$

If multiple insemination and sperm storage occur, the subroutine MALELOCI assigns male fish to each female. The number of males assigned to each female is between zero and the maximum allowed (an input variable between 1 and 5). The males are partitioned according to the user specified frequencies of occurrence of one male per female, two males per female, etc. The choice of individuals can be influenced by sexual and/or fecundity selection, if desired.

After the initial population has been established, a summary of the input data is generated and the gestation period loop begins. Each iteration, or time step, in this loop represents a gestation period of 28 days (the length of the gestation period can be specified by the user). The population is tested by POPTEST for valid size (at least two fish), and valid number of females (at least one), to continue.

Next the subroutine EXPOSURE is called to simulate toxicant exposure. The cumulative survival (Equation 6) of each fish is compared to a random number. If the cumulative survival is less than that random number, the fish dies. The population is tested for valid size to maintain itself. The subroutine PRINTRESULT is called to print a summary of results. The user specifies what information is to be included.

The subroutine MORTALITY is then called to determine whether a fish dies of natural causes during the current time step. The natural time-to-death (Equation 2) is multiplied by the factor

$$
\text { [1 - (LONGEVITY * PROBABILITY)] }
$$


where PROBABILITY is the total population divided by the carrying capacity, and LONGEVITY is a parameter was introduced to adjust the longevity. If winter is scheduled to occur in the current gestation period, the winter time-to-death is used in the above calculation. The fish's age is compared to the adjusted natural (or winter) time-todeath to see if the fish will live for one more gestation period. A test is also made to determine if the fish has exceeded the (user specified) maximum number of gestation periods allowed. The population is tested again for valid size to continue.

If winter does not occur during the current geststion period, breeding is then simulated by the subroutine BREEDING. Male fish must exceed a user-specified lower weight limit before they can breed. This limit can be based on genotype, if desired. In the case that multiple insemination does not occur, one male is assigned to each female (there must be at least one male) by MALELOCI. This choice may be completely random or influenced by sexual selection, according to the user's specification.

The subroutine BROODSIZE assigns a maximum brood size to each breeding female and assigns an age to each brood. A linear relationship is assumed between the weight of the mother fish and the maximum possible number of offspring her brood can contain (Mulvey et al., Vondracek et al ,1988).

MAXIMUM BROODSIZE = SLOPE*WEIGHT + INTERCEPT

WEIGHT is the mother's weight and SLOPE and INTERCEPT are user-supplied constants. When fecundity selection is included, there will be a separate set of constants for each genotype per locus in which fecundity selection is a factor.

Actual brood sizes are determined in the main program according to population constraints (Taylor, 1990).

$$
\text { ACTUAL BROODSIZE = MAXIMUM BROODSIZE }\left(1-\frac{\text { BNMPOP }}{\mathrm{K}}\right)
$$

where BNMPOP is the population size before natural mortality and $\mathrm{K}$ is the carrying capacity. The neonate population is the sum of the actual broods of each adult female in the population. If the addition of the new fish causes the population to exceed the maximum size limit, the program terminates.

The fish from the previous gestation period get one gestation period older. If it is not winter, growth is simulated by the subroutine GROWTH. The growth of individual fish is assumed to follow the logistic equation (Equation 1). The surviving fish are added to the fish born during the new gestation period. The new fish are assigned genotypes by SELECTGENO. A random number generator is initiated to choose the first allele of the genotype of each locus from the female and the second allele from a male assigned to that female. In the case of meiotic drive/gametic selection, the frequency of selection of maternal and/or paternal alleles may be specified. Size, sex, age, growth rate and natural times-to-death (Equation 2) are assigned to each new fish by CREATE. Cumulative survival (Equation 6) and median times-to-death due to exposure (Equation 4) are calculated by CALC for the survivors and the neonates. 
The subroutine CANN is called to simulate density and size-dependent mortality. A linear relationship is assumed between a fish's size and the probability that it will succumb to size-dependent predation, including cannabilism. For $\mathrm{W}>\mathrm{W}_{\min }$ :

$$
\mathrm{C}=\mathrm{C}_{\max }+\mathrm{C}_{\text {slope }} * \mathrm{~W}
$$

where $\mathrm{C}=$ the probability of predation

$\mathrm{C}_{\max }=$ the user-specified maximum probability of density and size-dependent mortality

$\mathrm{C}_{\text {slope }}=$ the user-specified slope, always negative

$\mathrm{W}_{\min }=$ the user-specified minimum weight

For $\mathrm{W} \leq \mathrm{W}_{\min }, \mathrm{C}=\mathrm{C}_{\max } . \mathrm{C}$ is then multiplied by the factor POP/K , or the population size divided by the carrying capacity, to incorporate the effect of competition on density and size-dependent mortality. $\mathrm{C}$ is compared to a random number to determine whether the fish is dies.

A user-specified number of migrating fish can be added to the population each gestation period (the number of immigrants can be different in winter). CREATE and CALC are called to assign characteristics to the immigrant fish, then they are added to the native population. If multiple insemination and sperm storage occur, MALELOCI is then called to assign male fish to females for the entire population.

The characteristics of each fish are printed if requested by the user. If the simulation has gone through the desired number of gestation periods, a new simulation is started. Otherwise, control passes to the top of the gestation period loop. 
The input variables, in the order that they are read in:

NUMLOCI - number of loci

SELECTION - Does Meiotic drive or Gametic selection occur? (T or F)

SSELECTION - Does Sexual selection occur? (T or F)

FSELECTION - Does Fecundity selection occur? (T or F)

MSELECTION - Does the weight limit in mg for which males may begin to breed differ for each genotype of specific locus? ( $\mathrm{T}$ or $\mathrm{F}$ )

LOCILABEL*10 - loci label(s)

NUMGENO - number of genotypes

REFGENO*2 - reference genotypes

WHICHLOCI - Is sexual selection indicated for this locus? (T or F)

FWHICHLOCI - Is fecundity selection indicated for this locus? (T or F)

MWHICHLOCI - Is male breeding weight limit differ per genotype indicated for this locus? (T or F)

SEXCHAR - Is sexual selection for this locus for the Male, Female, or Both? (M or F or B)

GENOTYPE*2 - genotype label(s)

GENOFREQ - genotype frequencies

GENOBETAS - genotype betas

MALLELE1, FALLELE1 - male and female first allele Meiotic drive/Gametic selection frequency

MALLELE2, FALLELE2 - male and female second allele Meiotic drive/Gametic selection frequency

MSEXFREQ, FSEXFREQ - male and female Sexual selection frequency

FUPPERWGT, FLOWERWGT - female's weight limits, of wet mass in $\mathrm{mg}$ for brood relation for fecundity selection

FSLOPE - slope coefficient for brood relation for fecundity selection

FINTERCEPT - intercept coefficient for brood relation for fecundity selection

MWGTLMT - male weight limit in mg for breeding

MBETA, FBETA - male and female betas (natural mortality) 
MSCALE, FSCALE - male and female scales (natural mortality)

LONGEVITY - proportional longevity

MMAXGEN, FMAXGEN - male and female maximum number of gestation periods

MWBETA, FWBETA - male and female betas (winter natural mortality)

MWSCALE, FWSCALE - male and female scales (winter natural mortality)

WW, WD - frequency and duration of winter

MMEAN, FMEAN, MSD, FSD - male and female mean weights and standard deviations

PDF - Is the probability density function lognormal? (T or F)

MMAX, FMAX, MMIN, FMIN - male and female maximum and minimum weights

MGRM, FGRM, MGRSD, FGRSD - male and female growth rates and standard deviations

MSHAPE, FSHAPE - male and female size shape factors (individual growth)

BASE - hazard model intercept

SCALE - hazard model scale parameter

DURATION1, DURATION2 - durations of exposure

GPT - gestation period in which the duration of exposure changes

SHIFT - the median shift; usually 0.693147 ; also the median shift is equivalent to exp (w)

SIZEBETA - size beta

SEXBETA - sex beta

FORM - indicates if sizebeta is in the log transform ( $T$ or F)

EXPOSE - frequency of exposure

$\mathrm{K}$ - carrying capacity

WGTLMT - minimum male weight (breeding)

CNTLMT - maximum male breeding per gestation period

UPPERWGT, LOWERWGT - female's weight limits, of wet mass in mg for brood relation

SLOPE - slope coefficient for brood relation

INTERCEPT - intercept coefficient for brood relation 
MAXC - density and size-dependent mortality coefficient

CSLOPE - slope coefficient (density and size-dependent mortality)

MULTI - Does multiple insemination and sperm storage occur? (T or F)

CMALES - maximum number of males per female

MALEFREQ - frequencies of occurrence for 1 to 5 males per female

REFSEX - reference sex

SEX RATIO - seX ratio

LENGEN - length of gestation period

If Batch routines are used, additional input variables are read in:

INITPOP - number of individuals in the initial population

IMMPOP - number of individuals migrating into the population

WIMMPOP - number of individuals migrating into the population during winter

NUMSIM - number of simulations

NUMGEN - number of gestation periods

GO, GC, MO, MC, PS - output file indicators

NUMOUT - number of gestation periods to output to Gen_Cut.dat or Gen_Out.dat

SELECTOUT - users selection of output to Gen_Cut.dat and/or Gen_Out.dat, random or multiple

SIMNUM, GENNUM - simulation, gestation period to output to Gen_Cut.dat and/or Gen_Out.dat 


\section{REFERENCES}

Diamond, S.A., M.C. Newman, M. Mulvey, P.M. Dixon and D. Martinson. 1989. Allozyme genotype and time to death of mosquitofish, Gambusia affinis (Baird and Girard), during acute exposure to inorganic mercury. Environ. Toxicol. and Chem. 8:613-622.

Dixon, P.M. and M.C. Newman. 1991. Analyzing toxicity data using statistical models for time-to-death: an introduction. In Metal Ecotoxicology, Concepts and Applications. Newman, M.C. and McIntosh, A.W. (Chelsea, MI: Lewis Publishers) pp. 207-242.

Hernandez-Martich, J.D. and M.H. Smith. 1990. Patterns of genetic variation in eastern mosquitofish (Gambusia holbrooki Girard) from the piedmont and coastal plain of three drainages. Copeia 1190:619-630.

Kennedy, W.J., Jr. and J.E. Gentle. 1980. Statistical Computing. (New York: Marcel Dekker, Inc.) pp. 211-212.

Krumholz, L.A. 1948. Reproduction in the western mosquitofish Gambusia affinis affinis (Baird and Girard) and its use in mosquito control. Ecol.Monogr. 18(1):3-42.

Mulvey, M. et al. Unpublished data.

Newman, M.C., S.A. Diamond, M. Mulvey and P. Dixon. 1989. Allozyme and time to death of mosquitofish, Gambusia affinis (Baird and Girard) during acute mercury exposure: a comparison of arsenate and inorganic mercury. Aquat. Toxicol. 15:141-156.

Newman, M.C. and M.S. Aplin. 1992. Enhancing toxicity data interpretation and prediction of ecological risk with survival time modeling: an illustration using sodium chloride toxicity to mosquitofish (Gambusia holbrooki). Aquat. Toxicol. 23: 85-96.

Philippi, T.E., M.P. Carpenter, T.J. Case and M.E. Gilpin. 1987. Drosophila population dynamics: chaos and extinction. Ecology 68:154-159.

Pinder, J.E. III, J.G. Wiener and M.H. Smith. 1978. The Weibull distribution: a new method of summarizing survivorship data. Ecology 59:175-179.

Taylor, B.E. 1990 . Personal communication.

Vondracek, B., W.A. Wurtsbaugh and J. J. Cech, Jr. 1988. Growth and reproduction of the mosquitofish, Gambusia affinis, in relation to temperature and ration level: consequences for life history. Environ. Biol. Fishes 21:45-57. 
Outline of files and routines for STResS

Main Program - STResS.for

I. Data Entry for

Edit Data

Get_Data

Cat_One
Cat_Two
Cat_Three
Cat_Four
Cat_Five
Cat_Six
Cat_Seven
Cat_Eight
Cat_Nine
Test_Data

II. Select.for

Select_Output

TestResults

III. IandM.for

Random_Gen

I_Random

Handler

Create Contig

Read_Contig

IV. CreatePop.for

Create

AssignSex

GetGeno

GrowthRate

NandW

Weights

Calc

Growth

V. Cause Death.for

Exposure

Cann

Mortality

VI. Breeding.for

SelectGeno

BroodSize

CalcBrood_A

CalcBrood_B

MaleLoci 
VII. Util.for

SwitchFish

PopTest

SortGeno

VIII. Print_All.for

PrintResult

PrintChar

SummaryOne

SummaryTwo

SortMTTD 
PROGRAM :

\section{STResS \\ Simulated Toxicant - Related Stress}

WRITTEN BY :

DAWN GREENE

PROGRAM SPECIFICATIONS :

\section{DEC FORTRAN v. 6.2}

This program receives the genetics and population data, the number of simulations to be done and the number of gestation periods to be processed for each simulation. A complete list of definitions and ranges for each variable are listed in the tables near the end.

Each simulation uses random number generators to create the characteristics of the initial population. For each gestation period the individuals are exposed to a toxicant (based on the frequency and duration of exposure; however, the duration can be changed once after a user specified number of gestation periods), the survivors are subjected to natural mortality or winter mortality (dependent on the frequency and duration of winter). These survivors are then allowed to breed, grow, and age; however, during winter they do not breed or grow. The population as a whole is subjected to density and size-dependent mortality. Finally, by using the same random process used to create the initial population, a migrating group of a specific number of individuals is created and added to the final population. Thus one gestation period is completed.

Abnormal termination occurs when the population is less than is required for the next step. Also, when the population exceeds the set maximum limit of 20,000 individuals, termination occurs.

\section{PROGRAM DESIGN :}

The initial data are received from either a prepared or modified data file, or interactively. When the data are entered interactively, a data file of a given name can then be created. Modifications can be made to the data file once it's entered. These modifications are made interactively. The following is entered interactively: number of simulations, number of gestation periods, initial population, migrating population, winter migrating population and the outputs desired.

The simulated initial population is created by randomly selecting and assigning a genotype for each locus (based on the genotype frequency) to each individual, assigning sex to each individual (based on the sex ratio), assigning weight (which is randomly calculated according to sex, mean, standard deviation, and pdf) to each individual, assigning an initial age in days, cumulative survival for exposure, median time to death, natural time to death, growth rate, and winter time to death for each individual in the initial population. Each gravid female, determined by female sexual selection. is assigned a brood size, which is linearly related to her weight which may be effected by fecundity selection selection; and an initial age for her brood is also assigned. If multiple insemination and 
sperm storage takes place, adult male(s) of adequate size are selected at random, based on male sexual selection, whose genotypes are assigned to each gravid female with brood size greater than zero in the initial population.

The first gestation period of each simulation, the initial population is exposed to the stressor; otherwise, the current population is exposed according to the frequency of exposure. The survivors are subjected to natural or winter mortality, based on the frequency and duration of winter, every gestation period. If there is no multiple insemination and sperm storage, the genes of one randomly selected adult male are assigned for each gravid female in the current population. Using the percentage of deaths from natural mortality, and the percentage of births possible, the carrying capacity and the sum of the assigned brood sizes, the number of new individuals to be born is calculated. Each individual of this new population of juveniles is assigned genotypes chosen randomly or as affected by meiotic drive/gametic selection, from a female and her assigned male. Each juvenile is assigned an initial weight, in relation to age; and sex, natural time-to-death, winter time-to-death, growth rate, cumulative survival, and median time-to-death during toxicant exposure using the same process as the initial population. The original individuals who survived exposure and mortality are allowed to grow, age, and receive updated cumulative survival and median time-to-death. This surviving population is subjected to density and size-dependent mortality. The migrating populations are created in the same way as the initial population. The dead individual's characteristics are deleted from the current population and the new individual's characteristics are added to the current population and the current population is continually updated. If multiple insemination and sperm storage occur, gravid female(s) are subjected to the process of assigning male genotypes, brood sizes, and brood ages; this process is repeated every gestation period, with the exception of winter gestation periods when new births, individual growth, and sperm storage do not occur.

\section{MODULE SPECIFICATIONS :}

\section{MAIN PROGRAM: STRES.For}

PURPOSE:

The purpose of this program is to initialize counters; call the subroutines required to obtain the initial data, create the initial population, simulate death from exposure to a stressor, natural or winter mortality, simulate breeding, growth, death by density and size-dependent mortality and create a migrating group, maintain the simulation and the gestation period loops, and update the population and its characteristics.

\section{INPUT: $\quad$ See Input Data File Format or the table of definitions at the end.}

OUTPUT: In the main program, the current simulation and gestation period being processed, the number of males, and the number of females, the current population, and the median time-to-death for each gestation period is written to the screen. At the user's request, the above mentioned information is written to a file called PT_SN.DAT. Also, at the user's request, the median times to death for $25 \%, 50 \%$, and $75 \%$, and the population for every gestation period of every simulation, before and after exposure are written to two possible files; one with headings called MTTD_OUT.DAT, the other without headings called MTTD_CUT.DAT. The file produced without headings may be conveniently analyzed with standard statistical software, such as SAS, without editing

NORMAL EXITS: Completes process of all the simulations and gestation periods requested by user.

ERROR CONDITIONS: The population is less than required for the next step. 


\section{SUBROUTINE: ..... EDIT_DATA}

PURPOSE: The purpose of this subroutine is to receive the initial data either interactively or from a data file, call the subroutines required to modify, correct or edit the data file (at user request), test each data item for correct form and range, determine the output files needed by the user, and write INIT_OUT.DAT file.

\section{USAGE:}

CALL EDIT_DATA (parameters)

PARAMETERS: $\quad$ NumLoci, NumGeno, Duration1, Duration2, Expose, K, MShape, FShape, MaxBrood, CMales, GenoBetas, MaleFreq, GenoFreq, SexBeta, SizeBeta, Sexratio, LenGen, MBeta, FBeta, MMax, FMax, MMin, FMin, MGRM, FGRM, MGRSD, FGRSD, MScale, FScale, MMean, FMean, MSD, FSD, LowerWgt, UpperWgt, Intercept, Slope, Base, Scale, PDF, RefSex, LociLabel, GenoType, RefGeno, Multi, ImmPop, InitPop, NumSim, NumGen, Longevity, MMaxGen, FMaxGen, MaxC, CSlope, CntLmt, WgrLmt, FWBeta, FWScale, MWBeta, MWScale, WW, WD, WImmPop, Shift, GPt, Form, Selection, MAllele1, FAllele1, MAllele2, FAllele2, SSelection, WhichLoci, SexChar, MSexFreq, FSexFreq, FLowerWgt, FUpperWgt, FSlope, FIntercept, FMaxBrood, FSelection, FWhichLoci, MSelection, MWhichLoci, MWgtLmt

NORMAL EXITS: All data items, either read in from a data file or entered interactively, are within the appropriate ranges and of the correct form.

ERROR CONDITIONS: A data item is not within the appropriate ranges or it is not listed as the correct type. The first will produce an error message and the user is allowed to correct the error interactively. The other will terminate the program abruptly and a systems error message will appear on the screen.

\section{SUBROUTINE: GET_DATA}

PURPOSE: The purpose of this routine is to allow the user to modify or correct the previously entered file, or to edit a file interactively.

\section{USAGE: $\quad$ CALL GET_DATA (parameters)}

PARAMETERS: $\quad$ Ch, Errs, ErrorNum, GenoError, FreqError, BetaError, RefError, NumLoci, NumGeno, Duration1, Duration2, Expose, K, MShape, FShape, CMales, GenoBetas, MaleFreq, GenoFreq, SexBeta, SizeBeta, SexRatio, LenGen, MBeta, FBeta, MWBeta, FWBeta, MWScale, FWScale, WW, MMax, FMax, MMin, FMin, MGRM, FGRM, MGRSD, FGRSD, MScale, FScale, MaxC, CSlope, WgtLmt, CntLmt, MMean, FMean, MSD, FSD, LowerWgt; UpperWgt, Intercept, Slope, Base, Scale, PDF, RefSex, LociLabel, GenoType, RefGeno, Multi, Longevity, MMaxGen, FMaxGen, WD, GPt, Shift, Form, Selection, MAllele1, FAllele1, MAllele2, FAllele2, SSelection, WhichLoci, SexChar, MSexFreq, FSexFreq, FLowerWgt, FUpperWgt, FSlope, FIntercept, FMaxBrood, FSelection, FWhichLoci, MSelection, MWhichLoci, MWgtLmt

NORMAL EXITS: All data items, changes, or corrections required are successful, within their respective ranges, and any errors found are reported to the user to be corrected.

ERROR CONDITIONS: If a data item is not the correct type, then the program will terminate abruptly and a system's error message is written to the screen. Also, if there is an error when writing the new data to the data file, the program will terminate, the data file may be destroyed, and a system's error message will be written to 
the screen.

SUBROUTINE: CAT_ONE

PURPOSE: The purpose of this routine is to prompt the user and accept data interactively for modification or correction of the genotype and loci information. In the case of meiotic drive/gametic selection, it prompts the user and accepts the required data. This is also true in the case of sexual selection, fecundity selection, and male weight selection.

USAGE: $\quad$ CALL CAT_ONE (parameters)

PARAMETERS: $\quad$ Ch, NumLoci, NumGeno, GenoBetas, GenoFreq, LociLabel, GenoType, RefGeno, Selection, MAllelè1, FAllele1, MAllele2, FAllele2, SSelection, WhichLoci, SexChar, MSexFreq, FSexFreq, FLowerWgt, FUpperWgt, FSlope, FIntercept, FMaxBrood, FSelection, FWhichLoci, MSelection, MWhichLoci, MWgtLmt

NORMAL EXITS: All data items requested are received and accepted.

ERROR CONDITIONS: If a data item is not the correct data type, then the program will terminate abruptly and a system's error message is written to the screen.

\section{SUBROUTINE: CAT_TWO}

PURPOSE: The purpose of this routine is to prompt the user and accept data interactively for modification, correction, or interactive data entry of the natural mortality factors.

USAGE:

CALL CAT_TWO (parameters)

PARAMETERS: $\quad$ Ch, MBeta, FBeta, MScale, FScale, Longevity, MMaxGen, FMaxGen

NORMAL EXITS: $\quad$ All data items requested are received and accepted.

ERROR CONDITIONS: If a data item is not the correct data type, then the program will terminate abruptly and a system's error message is written to the screen.

\section{SUBROUTINE: CAT_THREE}

PURPOSE:

The purpose of this routine is to prompt the user and accept data interactively for modification, correction, or interactive data entry of the winter mortality factors.

USAGE:

CALL CAT_THREE (parameters)

PARAMETERS: $\quad$ Ch, MWBeta, FWBeta, MWScale, FWScale, WW, WD

NORMAL EXITS: " All data items requested are received and accepted. 
ERROR CONDITIONS: If a data item is not the correct data type, then the program will terminate abruptly and a system's error message is written to the screen.

\section{SUBROUTINE: CAT_FOUR}

PURPOSE: The purpose of this routine is to prompt the user and accept data interactively for modification, correction, or interactive data entry of the growth and size factors.

USAGE: $\quad$ CALL CAT_FOUR (parameters)

PARAMETERS: $\quad$ Ch, MMean, FMean, MSD, FSD, PDF, FGRM, MGRM, FGRSD, MGRSD, FMax, MMax, FMin, MMin, FShape, MShape

NORMAL EXITS: All data items requested are received and accepted.

ERROR CONDITIONS: If a data item is not the correct data type, then the program will terminate abruptly and a system's error message is written to the screen.

\section{SUBROUTINE: $\quad$ CAT_FIVE}

PURPOSE: The purpose of this routine is to prompt the user and accept data interactively for modification, correction, or interactive data entry of the exposure coefficients.

USAGE: $\quad$ CALL CAT_FIVE (parameters)

PARAMETERS: $\quad$ Ch, Base, Scale, Duration1, Duration2, GPt, Shift, SexBeta, SizeBeta, Form, Expose

NORMAL EXITS: $\quad$ All data items requested are received and accepted.

ERROR CONDITIONS: If a data item is not the correct data type, then the program will terminate abruptly and a system's error message is written to the screen.

\section{SUBROUTINE: CAT_SIX}

PURPOSE: The purpose of this routine is to prompt the user and accept data interactively for modification, correction, or interactive data entry of the breeding and brood relation coefficients. However, in the case of fecundity selection, the brood relation coefficients are accepted in CAT_ONE and only the breeding coefficients are required. Also, in the case of male weight selection, the weight limit for males to begin to breed is accepted in CAT_ONE.

USAGE: CALL CAT_SIX (parameters)

PARAMETERS: $\quad \mathrm{Ch}, \mathrm{K}$, UpperWgt, LowerWgt, Slope, Intercept, WgtLmt, CntLmt, FSelection, MSelection

NORMAL EXITS: $\quad$ All data items requested are received and accepted. 
ERROR CONDITIONS: If a data item is not the correct data type, then the program will terminate abruptly and a system's error message is written to the screen.

\section{SUBROUTINE: $\quad$ CAT_SEVEN}

PURPOSE: The purpose of this routine is to prompt the user and accept data interactively for modification, correction, or interactive data entry of the density and size-dependent mortality coefficients.

USAGE:

CALL CAT_SEVEN (parameters)

PARAMETERS: $\quad$ Ch, MaxC, CSlope

NORMAL EXITS: $\quad$ All data items requested are received and accepted.

ERROR CONDITIONS: If a data item is not the correct data type, then the program will terminate abruptly and a system's error message is written to the screen.

\section{SUBROUTINE: CAT_EIGHT}

PURPOSE: The purpose of this routine is to prompt the user and accept data interactively for modification, correction, or interactive data entry of the multiple insemination and sperm storage related information.

USAGE:

CALL CAT_EIGHT (parameters)

PARAMETERS: $\quad$ Ch, Multi, CMales, MaleFreq

NORMAL EXITS: All data items requested are received and accepted.

ERROR CONDITIONS: If a data item is not the correct data type, then the program will terminate abruptly and a system's error message is written to the screen.

\section{SUBROUTINE: $\quad$ CAT_NINE}

PURPOSE: $\quad$ The purpose of this routine is to prompt the user and accept data interactively for modification, correction, or interactive data entry of the reference sex, the sex ratio, and the length of a gestation period.

USAGE:

CALL CAT_NINE (parameters)

PARAMETERS:

Ch, RefSex, SexRatio, LenGen

NORMAL EXITS: All data items requested are received and accepted.

ERROR CONDITIONS: If a data item is not the correct data type, then the program will terminate abruptly and a system's error message is written to the screen. 
SUBROUTINE: : TEST_DATA

PURPOSE: The purpose of this routine is to test each data item received either from a data file or interactive entry for a given range and return any errors to the EDIT_DATA.

USAGE: $\quad$ CALL TEST_DATA (parameters)

PARAMETERS: NumLoci, NumGeno, Duration1, Duration2, Expose, K, MShape, FShape, CMales, GenoBetas, MaleFreq, GenoFreq, SexBeta, SizeBeta, SexRatio, LenGen, MBeta, FBeta, MWBeta, FWBeta, MWScale, FWScale, WW, MMax, FMax, MMin, FMin, MGRM, FGRM, MGRSD, FGRSD, MScale, FScale, MaxC, CSlope, WgtLmt, CntLmt, MMean, FMean, MSD, FSD, LowerWgt, UpperWgt, Intercept, Slope, Base, Scale, PDF, RefSex, LociLabel, GenoType, RefGeno, Multi, Longevity, MMaxGen, FMaxGen, WD, GPt, Shift, Form, Ch, Selection, MAllele1, FAllele1, MAllele2, FAllele2, Errs, ErrorNum, GenoError, FreqError, BetaError, RefError, AlleleError, SSelection, WhichLoci, SexChar, MSexFreq, FSexFreq, SexError, FecError, FLowerWgt, FUpperWgt, FSlope, FIntercept, FMaxBrood, FSelection, FWhichLoci, MSelection, MWhichLoci, MWgtLmt

NORMAL EXITS: All data items are within their respective ranges and the errors found are reported to the user to be corrected.

ERROR CONDITIONS: If a data item is not the correct type, then the program will terminate abruptly and a system's error message is written to the screen.

II.

SELECT.FOR

SUBROUTINE:

\section{SELECT_OUTPUT}

PURPOSE:

This routine writes a menu of output files and their descriptions to the screen. The user is allowed to select the specific output files needed and the specific simulation and gestation periods for GEN_CUT.DAT and/or GEN_CUT.DAT.

USAGE:

CALL SELECT_OUTPUT (parameters)

PARAMETERS: $\quad$ NumSim, NumGen, GO, GC, PS, MO, MC, N, Results

NORMAL EXITS: The user has selected the output files and simulations and gestation periods needed.

ERROR CONDITIONS: If the first number entered here is not the exact number of output files the user requests or if this number or any of the output file id numbers are not within their range, then an error message is written to the screen and the user is allowed to make corrections.

\section{SUBROUTINE: TEST_RESULTS}

PURPOSE: This routine is used only if the GEN_OUT or the GEN_CUT file is requested by the user. The simulations and gestation periods required for these files are tested and put in ascending order. 
USAGE:

CALL TESTRESULTS (parameters)

PARAMETERS: $\quad$ N, Results

NORMAL EXITS: The data are data type integer and within the respective ranges.

ERROR CONDITIONS: If the above condition is not true, then an error message is written to the screen and user is allowed to make corrections.

III.

IANDM.FOR

SUBROUTINE: $\quad$ RANDOM_GEN

REFERENCE: $\quad \ldots$ IMSL User's Manual, Stat/Library

Vol. 3, Ch. $16-20$, Version 1.0, April 1987

18.2 Basic Uniform Generators, pg. $963+$

PURPOSE: $\quad$ Generates pseudorandom numbers from a uniform $(0,1)$ distribution. The routine RNOPT is used to select the form of the generator. (This routine actually contains four pseudorandom number generators; a normal distribution, a log normal distribution, and two uniform distributions.)

USAGE: CALL RANDOM_GEN (parameters)

PARAMETERS: $\quad$ NR, Mean, SD, Code, $R$

EXTERNALS: $\quad$ RNOPT, RNSET, RNUN, UMACH, RNNOR, SSCAL, SADD, RNLNL, RNUNF

NORMAL EXITS: All requested random numbers are generated.

ERROR CONDITIONS: The number of random numbers to be generated must be greater than or equal to 1 .

SUBROUTINE: I_RANDOM

REFERENCE: $\quad$ IMSL User's Manual, Stat/Library

Vol. 3, Ch. $16-20$, Version 1.0, April 1987

18.2 Basic Uniform Generators, pg. $963+$

PURPOSE: $\quad$ Generates pseudorandom numbers from a uniform $(1, K)$ distribution. ( $K$ being any integer.) The routine RNOPT is used to select the form of the generator.

USAGE:

CALL I RANDOM (parameters)

PARAMETERS: $\quad$ NR, IR, $K$

EXTERNALS: $\quad$ RNOPT, RNSET, RNUND, UMACH 
NORMAL EXITS: All requested random numbers are generated.

ERROR CONDITIONS: The number of random numbers to be generated must be greater than or equal to 1 .

SUBROUTINE: HANDLER

REFERENCE: Condition - Handling Facilities, 9-17

Vax Fortran users manual

PURPOSE: This routine is a condition handler for system service failures.

USAGE: $\quad$ INTEGER*4 FUNCTION HANDLER (SIGARGS, MECHARGS)

PARAMETERS: $\quad$ INTEGER*4 SIGARGS(*), MECHARGS(5)

INCLUDE '(\$SSDEF)'

INCLUDE '(\$MTHDEF)'

NORMAL EXITS: System service failures are corrected.

SUBROUTINE: CREATE_CONTIG

REFERENCE: _ Using VMS Record Management Services, 7-5

Vax Fortran Users Manual

PURPOSE: $\quad$ USEROPEN routine to set block I/O bit and create the block I/O file.

USAGE: $\quad$ INTEGER FUNCTION CREATE_CONTIG (FAB, RAB, LUN)

PARAMETERS: INCLUDE '(\$FABDEF)'

INCLUDE '(\$RABDEF)'

INCLUDE '(\$SYSSRVNAM)'

RECORD /FABDEF/FAB, /RABDEF/RAB

NORMAL EXITS: File is created and opened.

ERROR CONDITIONS: The above conditions are not true, then the program terminates and a systems error message appears on the screen.

SUBROUTINE: - READ_CONTIG

REFERENCE: Using VMS Record Management Services, 7-5

Vax Fortran Users Manual

PURPOSE: - USEROPEN routine to set block I/O bit and open the block I/O file for reading.

USAGE: $\quad$ INTEGER FUNCTION READ_CONTIG (FAB, RAB, LUN) 
PARAMETERS:

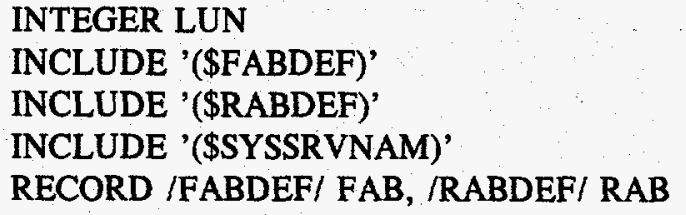

NORMAL EXITS: File is found and opened for reading.

ERROR CONDITIONS: The above conditions are not true, then the program terminates and a systems error message appears on the screen.

IV.

CREATEPOP.FOR

\section{SUBROUTINE: CREATE}

PURPOSE: $\quad$ This routine randomly selects and assigns a genotype for each locus, sex, weights, growth rates, age, natural and winter time-to-death to each individual in the initial population or the migrating papulation. Also this routine assigns sex, weights, growth rates, natural, and winter time-to-death to each individual in the new population of juveniles.

\section{USAGE: \\ CALL CREATE (parameters)}

PARAMETERS: S, ID, Tot, NumLoci, NumGeno, GenoFreq, Genotype, FishGeno, FTot, RefSex, FMean, FSD, MMean, MSD, PDF, FMin, FMax, MMin, MMax, FGRM, FGRSD, MGRM, MGRSD, LenGen, FMaxGen, MMaxGen, FShape, MShape, FBeta, MBeta, FScale, MScale, FWBeta, FWScale, MWBeta, MWScale, Fish, ErrorCode

NORMAL EXITS: The required characteristics are assigned to each individual in the initial population, the migrating populations or the new population.

\section{SUBROUTINE: ASSIGNSEX}

PURPOSE: $\quad$ This routine assigns a sex, based on the sexratio, to each individual of either the initial population, the migrating populations, or the new population.

USAGE: CALL ASSIGNSEX (parameters)

PARAMETERS: I, Pop, Q, RefSex, Fish

NORMAL EXITS: A sex value is assigned to each individual in the initial population, the migrating populations, or the new population.

SUBROUTINE: GETGENO 
PURPOSE:

This routine randomly selects and assigns a genotype for each locus, based on it's frequency, to each individual in the initial population or the migrating populations.

USAGE:

CALL GETGENO (parameters)

PARAMETERS:

I, InitPop, NumLoci, NumGeno, GenoFreq, GenoType, FishGeno

NORMAL EXITS: One genotype for each locus is selected and assigned to each individual in the initial population or in the migrating populations.

\section{SUBROUTINE: $\quad$ GROWTHRATE}

PURPOSE: This routine assigns a growth rate to each individual in either the initial population, the migrating populations or the new population. A random number generator is called to determine the growth rate to be assigned. This random number is based on the male or female growth rate means and standard deviations.

USAGE:

CALL GROWTHRATE (parameters)

PARAMETERS: $\quad$ I, Pop, Mean, SD, Fish

NORMAL EXITS: $\quad$ Each individual has been assigned a growth rate.

\section{SUBROUTINE: $\quad$ NANDW}

PURPOSE: The purpose of this routine is to determine natural and winter time-to-death for each individual of either the initial population, the migrating populations, or the new population. A random number generator is used to chose normally distributed random numbers which are calculated with scale and beta coefficients to determine the natural and winter times to death.

USAGE: CALL NANDW (parameters)

PARAMETERS: $\quad$ MB, FB, MS, FS, J, Fish, FPop, Pop, ID

NORMAL EXITS: $\quad$ Each individual is assigned a natural and winter times to death.

\section{SUBROUTINE: WEIGHTS}

PURPOSE: $\quad$ This program assigns randomly chosen weights to each individual in either the initial population, the migrating populations or the new population. This process, based on the PDF, chooses a random number generator which randomly chooses its weight in $\mathrm{mg}$ of wet mass.

\section{USAGE: $\quad$ CALL WEIGHTS (parameters)}

PARAMETERS: InitPop, Pop, Mean, SD, PDF, Min, Max, I, Fish

NORMAL EXITS: Each individual is assigned a reasonable size and is returned to the main program. 
SUBROUTINE: $\quad$ CALC

PURPOSE: The purpose of this routine is to calculate and assign the Cumulative Survival and the Median Time-to-death due to exposure to a stressor to each individual. This routine also calculates the individual's own betas. NOTES: Shift $=\exp (W)$. Also, if FishGeno is equal to the RefGeno then its GenoBeta is treated as equaling zero when determining the sum for the XBeta for calculating the Cumulative Survival and the Median Time-to-death.

USAGE: $\quad$ CALL CALC (parameters)

PARAMETERS: Pop, P, NumLoci, NumGeno, FishGeno, GenoType, RefGeno, GenoBetas, SexBeta, SizeBeta, Base, Scale, Duration, Shift, Form, Fish

NORMAL EXITS: All individuals are assigned cumulative survival rates and median times to death.

SUBROUTINE:

GROWTH

PURPOSE: $\quad$ This routine uses the growth rate, shape, and the individual's current weight to calculate a new weight for each individual, allowing each to grow. Also, this routine calculates the age of each individual in the initial or the migrating populations, based on the individual's weight.

USAGE:

CALL GROWTH (parameters)

PARAMETERS:

FShape, MShape, Fish

Flag, Pop, FPop, I, LenGen, FMaxGen, MMaxGen, FMin, MMin, FMax, MMax,

NORMAL EXITS: $\quad$ Each individual is given a new weight or assigned an initial age.

V.

\section{CAUSE_DEATH.FOR}

\section{SUBROUTINE: $\quad$ EXPOSURE}

PURPOSE: This routine simulates death due to exposure to a stressor. A random number generator is used to find a number to compare with the individual's cumulative survival rate.

USAGE:

CALL EXPOSURE (parameters)

PARAMETERS: $\quad \therefore$ NumLoci, Pop, FPop, Male, Fish, FishGeno, Brood, BAges, Assign

NORMAL EXITS: ... Each individual is tested, its survival is determined, and all survivors are replaced in the array.

SUBROUTINE: CANN 
PURPOSE:

This routine simulates death due to density and size-dependent mortality. A random number generator is used to find a number to compare with an individual's calculated $\mathbf{C}$ to determine if that individual lives or dies.

USAGE:

CALL CANN (parameters)

PARAMETERS:

Bages, FishGeno

Pop, ANMPop, FPop, K, MaxC, CSlope, FMin, MMin, Fish, Assign, Male, Brood,

NORMAL EXITS: Each individual is tested, its survival is determined, and all survivors are replaced in the array.

\section{SUBROUTINE: $\quad \because \quad$ MORTALITY}

PURPOSE: This routine simulates death due to natural causes or natural causes during winter. This is done by testing age and natural time-to-death. If the length of a gestation period plus the natural time to death multiplied by one minus longevity multiplied by population divided by carrying capacity is greater than the age then the individual dies.

USAGE:

CALL MORTALITY (parameters)

PARAMETERS: $\quad$ X, NumLoci, LenGen, Pop, FPop, K, Longevity, FMaxGen, MMaxGen, Brood, BAges, Fish, FishGeno, Assign, Male

NORMAL EXITS: $\quad$ Each individual is tested, its survival is determined and all survivors are replaced in the array.

VI.

BREEDING.FOR

\section{SUBROUTINE: - SELECTGENO}

PURPOSE: $\quad$ The purpose of this routine is to assign genotypes to each individual in the new population. A random number generator is initiated to chose the first portion of a genotype of each locus from the female and the second portion of that genotype from a male whose genotypes have been assigned to that female. This genotype selection may be affected by Meiotic drive/Gametic selection.

USAGE: $\quad$ SELECTGENO (parameters)

PARAMETERS: NewPop, FPop, Brood, BAges, NumLoci, CMales, FishGeno, Assign, Male, Multi, NewFish, NewGeno, Selection, MAllele1, FAllele1, MAllele2, FAllele2, ErrorCode

NORMAL EXITS: All individuals in the new population is assigned one genotype for each locus.

ERROR CONDITIONS: The new population exceeds the total number possible for all broods. 
SUBROUTINE:

REFERENCE:
BROODSIZE

"GROWTH AND REPRODUCTION OF THE MOSQUITOFISH, GAMBUSIA AFFINIS, IN RELATION TO TEMPERATURE AND RATION LEVEL: CONSEQUENCES FOR LIFE HISTORY"

BY BRUCE VONDRACEK, WAYNE A. WURTSBAUGH, AND JOSEPH J. CECH,JR. ENVIRONMENTAL BIOLOGY OF FISHES, VOL. 21, NO. 1, PP. $45-57,1988$

PURPOSE:

This routine uses the relation of female weight in $\mathrm{mg}$ of wet mass to brood size and assigns a brood size to each gravid female. Also, an age between 0 days and length of the gestation period is assigned to each gravid female, this age is given to each individual in her brood. Sexual selection and fecundity selection determines the chances for a female to be gravid. In the case that she is not gravid, then she does not receive a brood size.

USAGE:

CALL BROODSIZE (parameters)

PARAMETERS: $\quad$ FPop, LenGen, Fish, LowerWgt, UpperWgt, MaxBrood, Slope, Intercept, BAges, Brood, SSelection, WhichLoci, SexChar, FSexFreq, GenoType, NumLoci, NumGeno, FLowerWgt, FUpperWgt, FSlope, FIntercept, FMaxBrood, FSelection, FWhichLoci

NORMAL EXITS: $\quad$ All gravid females are assigned a brood size and age.

\section{SUBROUTINE: CALCBROOD_A}

PURPOSE: $\quad$ This routine, which is called by BROODSIZE, uses the relation of female weight in $\mathrm{mg}$ of wet mass to broodsize and assigns a brood size to each gravid female. Also, an age between 0 days and length of the gestation period is assigned to each gravid female, this age is given to each individual in her brood. Fecundity selection determine the chances for a female to be gravid. In the case that she is not gravid, then she does not receive a brood size.

USAGE: CALL CALCBROOD_A (parameters)

PARAMETERS: Id, Fish, BAges, Brood, GenoType, NumLoci, NumGeno, FLowerWgt, FUpperWgt, FSlope, FIntercept, FMaxBrood, FWhichLoci

NORMAL EXITS: All gravid females are assigned a brood size.

\section{SUBROUTINE: $\quad$ CALCBROOD_B}

PURPOSE: $\quad$ This routine, which is called by BROODSIZE, uses the relation of female weight in $\mathrm{mg}$ of wet mass to brood size and assigns a brood size to each gravid female. Also, an age between 0 days and length of the gestation period is assigned to each gravid female, this age is given to each individual in her brood.

USAGE: $\quad$ CALL CALCBROOD_B (parameters)

PARAMETERS: Id, Fish, LowerWgt, UpperWgt, MaxBrood, Slope, Intercept, BAges, Brood

NORMAL EXITS: All gravid females are assigned a brood size. 


\section{SUBROUTINE: MALELOCI}

PURPOSE: $\quad$ This routine randomly selects an adult male or males, determined by sexual selection, from the whole population and assigns that male's genotypes to a given gravid female. This is done every gestation period for every gravid female. This routine calls BROODSIZE first to determine whether or not the female is gravid.

USAGE:

CALL MALELOCI (parameters)

PARAMETERS: $\quad$ Multi, CntLmt, WgtLmt, MaleFreq, CMales, Pop, FPop, NumLoci, FishGeno, Fish, LenGen, LowerWgt, UpperWgt, Slope, Intercept, BAges, Brood, Male, Assign, Availability, SSelection, WhichLoci, SexChar, MSexFreq, FSexFreq, FLowerWgt, FUpperWgt, FSlope, FIntercept, FMaxBrood, FSelection, FWhichLoci, MSelection, MWhichLoci, MWgtLmt

NORMAL EXITS: All gravid females are assigned male genotypes.

VII.

UTIL.FOR

SUBROUTINE:

SWITCHFISH

PURPOSE:

This routine switches the individual's characteristics from the temporary arrays to the original arrays.

USAGE:

CALL SWITCHFISH (parameters)

PARAMETERS:

Pop, NewFish, NumLoci, NewGeno, FPop, NewMale, NewAssign, Fish, FishGeno, Male, Assign

NORMAL EXITS: The arrays are successfully transferred.

\section{SUBROUTINE: $\quad$ POPTEST}

PURPOSE: $\quad$ The purpose of this routine is to test the male and the female populations, and the population as a whole for valid amounts of individuals to continue the simulation.

USAGE: $\quad$ CALL POPTEST (parameters)

PARAMETERS: Pop, FPop, Multi, PS, ErrorFound

NORMAL EXITS: The populations are valid.

ERROR CONDITIONS: The populations are below the valid limits; in which, a message is written to the screen and the error found indicator returns to the main program. 
PURPOSE: The purpose for this routine is to put the brood relation coefficients for fecundity selection, the sex frequencies for sexual selection, the allele frequencies for meiotic drive/gametic selection, the geno types, betas, and frequencies for each locus in ascending order according to the genotypes' frequency.

USAGE: $\quad$ CALL SORTGENOS (parameters)

PARAMETERS: NumGeno, GenoBetas, GenoFreq, GenoType, Loci, Selection, MAllele1, FAllele1, MAllele2, FAllele2, SSelection, SexChar, MSexFreq, FSexFreq, FLowerWgt, FUpperWgt, FSlope, FIntercept, FMaxBrood, FSelection, MSelection, MWgtLmt

NORMAL EXITS: All the geno types, betas, and frequencies, etc. are correctly sorted in ascending order according to their frequencies.

VIII.

PRINT_ALL.FOR

SUBROUTINE:

PRINTRESULT

PURPOSE:

This routine calls PRINTCHAR to format and write the characteristics of each individual to the specified file as requested. Then the MTTD files are formatted and written, as requested.

USAGE:

CALL PRINTRESULT (parameters)

PARAMETERS: GO, GC, MO, MC, PS, Sim, Gen, S, Pop, Fish, FishGeno, NumLoci, NumGeno, GenoType, Multi, FPop, Male, Assign, LociLabel, Results, X, PageNum, Winter

NORMAL EXITS: The characteristics of each individual are written to the specified file.

SUBROUTINE: PRINTCHAR

PURPOSE: $\quad$ This routine formats and writes the characteristics of each individual to the specified file.

USAGE: $\quad$ CALL PRINTCHAR (parameters)

PARAMETERS: $\quad$ GO, GC, Sim, Gen, String, Ch, Ch2, Pop, Fish, FishGeno, NumLoci, NumGeno, GenoType, Multi, FPop, Male, Assign, LociLabel, Results, X, PageNum, Winter

NORMAL EXITS: The characteristics of each individual are written to the specified file.

\section{SUBROUTINE: $\quad$ SUMMARYONE}

PURPOSE: This routine is called by PRINTCHAR to sort and to determine the median weights (mg) of the female population and of the male population.

USAGE: $\quad$ CALL SUMMARYONE (parameters) 
PARAMETERS: $\quad$ Pop, FPop, Fish, Wgts

NORMAL EXITS: The $25 \%, 50 \%$, and $75 \%$ medians of weight for sex are returned to PRINTCHAR.

SUBROUTINE: $\quad$ SUMMARYTWO

PURPOSE: This routine is called by PRINTCHAR to find the genotype frequencies for each locus for the current population.

USAGE: $\quad$ CALL SUMMARYTWO (parameters)

PARAMETERS: $\quad$ NumGeno, NumLoci, Pop, FishGeno, GenoType, Freq

NORMAL EXITS: The frequencies are found and returned to PRINTCHAR.

SUBROUTINE: $\quad$ SORTMTTD

PURPOSE: This routine sorts the Median Times To Death of each individual and determines the 25\%, $50 \%$, and $75 \%$ medians and returns these values to the main program.

USAGE: CALL SORTMTTD (parameters)

PARAMETERS: Fish, Pop, MTTD

NORMAL EXITS: The values above are found and returned. 
Outline of files and routines for STRS (Batch routines)

Satellite Program - STRS.com

Main Program - STRS.for

I. STRS Data.for

Edit Data

Test_Data

TestResults

II. IandM.for

Random_Gen

I Random

Handler

Create Contig

Read_Contig

III. CreatePop. for

Create

AssignSex

GetGeno

GrowthRate

NandW

Weights

Calc

Growth

IV. Cause_Death.for

Exposure

Cann

Mortality

V. Breeding.for

SelectGeno

BroodSize

CalcBrood A

CalcBrood_B

MaleLoci

VI. STRS_Util.for

SwitchFish

PopTest

SortGeno

VII. STRS_Print.for

PrintResult

PrintChar

SummaryOne

SummaryTwo 


\section{SortMTTD}

Satellite Program - Make.for

I. Make.for

SelectOutput

TestResults 
MODULE SPECIFICATIONS :

MAIN PROGRAM: $\quad$ STRS.Com

PURPOSE:

of STRS.Exe.

The purpose of this program, a command routine, is to actually preform the batch run

NORMAL EXITS: $\quad$ Completes batch run of STRS.Exe.

ERROR CONDITIONS: Error in data file or batch job is interrupted.

\section{MAIN PROGRAM: $\quad$ STRS.For}

PURPOSE: The purpose of this program is to initialize counters; call the subroutines required to obtain the initial data, create the initial population, simulate death from exposure to a stressor, natural or winter mortality, simulate breeding, growth, death by density and size-dependent mortality and create a migrating group, maintain the simulation and the gestation period loops, and update the population and its characteristics.

INPUT: $\quad$ See Input Data File Format or the table of definitions at the end.

OUTPUT: In the main program, at the user's request, the current simulation and gestation period being processed, the number of males, and the number of females, the current population, and the median time-todeath for each gestation period is written to a file called PT_SN.DAT. Also, at the user's request, the median times to death for $25 \%, 50 \%$, and $75 \%$, and the population for every gestation period of every simulation, before and after exposure are written to two possible files; one with headings called MTTD_OUT.DAT, the other without headings called MTTD_CUT.DAT.

NORMAL EXITS: Completes process of all the simulations and gestation periods requested by user.

ERROR CONDITIONS: The population is less than required for the next step.

I.

STRS_DATA.FOR

SUBROUTINE: EDIT_DATA

PURPOSE: $\quad$ The purpose of this subroutine is to receive the initial data from a data file, call the subroutine required to test each data item for correct form and range, and write INIT_OUT.DAT file.

USAGE: $\quad$ CALL EDIT_DATA (parameters)

PARAMETERS: NumLoci, NumGeno, Duration1, Duration2, Expose, K, MShape, FShape, MaxBrood, 
CMales, GenoBetas, MaleFreq, GenoFreq, SexBeta, SizeBeta, Sexratio, LenGen, MBeta, FBeta, MMax, FMax, MMin, FMin, MGRM, FGRM, MGRSD, FGRSD, MScale, FScale, MMean, FMean, MSD, FSD, LowerWgt, UpperWgt, Intercept, Slope, Base, Scale, PDF, RefSex, LociLabel, GenoType, RefGeno, Multi, ImmPop, InitPop, NumSim, NumGen, Longevity, MMaxGen, FMaxGen, MaxC, CSlope, CntLmt, WgrLmt, FWBeta, FWScale, MWBeta, MWScale, WW, WD, WImmPop, Shift, GPt, Form, Selection, MAllele1, FAllele1, MAllele2, FAllele2, SSelection, WhichLoci, SexChar, MSexFreq, FSexFreq, FLowerWgt, FUpperWgt, FSlope, FIntercept, FMaxBrood, FSelection, FWhichLoci, MSelection, MWhichLoci, MWgtLmt, GO, GC, MO, MC, PS, N, Results

NORMAL EXITS: All data items read in from a data file are within the appropriate ranges and of the correct form.

ERROR CONDITIONS: A data item is not within the appropriate ranges or it is not listed as the correct type. The first will produce an error message. The other will terminate the program abruptly and a systems error message will appear on the screen.

\section{SUBROUTINE: $\quad$ TEST_DATA}

PURPOSE: The purpose of this routine is to test each data item received from a data file and return any errors to the EDIT_DATA.

USAGE: $\quad$ CALL TEST_DATA (parameters)

PARAMETERS: NumLoci, NumGeno, Duration1, Duration2, Expose, K, MShape, FShape, CMales, GenoBetas, MaleFreq, GenoFreq, SexBeta, SizeBeta, SexRatio, LenGen, MBeta, FBeta, MWBeta, FWBeta, MWScale, FWScale, WW, MMax, FMax, MMin, FMin, MGRM, FGRM, MGRSD, FGRSD, MScale, FScale, MaxC, CSlope, WgtLmt, CntLmt, MMean, FMean, MSD, FSD, LowerWgt, UpperWgt, Intercept, Slope, Base, Scale, PDF, RefSex, LociLabel, GenoType, RefGeno, Multi, Longevity, MMaxGen, FMaxGen, WD, GPt, Shift, Form, Ch, Selection, MAllele1, FAllele1, MAllele2, FAllele2, Errs, ErrorNum, GenoError, FreqError, BetaError, RefError, AlleleError, SSelection, WhichLoci, SexChar, MSexFreq, FSexFreq, SexError, FecError, FLowerWgt, FUpperWgt, FSlope, FIntercept, FMaxBrood, FSelection, FWhichLoci, MSelection, MWhichLoci, MWgtLmt

NORMAL EXITS: All data items are within their respective ranges and the errors found are reported to the user to be corrected.

ERROR CONDITIONS: If a data item is not the correct type, then the program will terminate abruptly and a system's error message is written to the screen.

\section{SUBROUTINE: TEST_RESULTS}

PURPOSE: $\quad$ This routine is used only if the GEN_OUT or the GEN_CUT file is requested by the user. The simulations and gestation periods required for these files are tested and put in ascending order.

USAGE: $\quad$ CALL TESTRESULTS (parameters)

PARAMETERS: N $\quad$ Nesults

NORMAL EXITS: The data are data type integer and within the respective ranges. 
ERROR CONDITIONS: If the above condition is not true, then an error message is written to the screen and user is allowed to make corrections.

II.

STRS_UTIL.FOR

SUBROUTINE:

SWITCHFISH

PURPOSE:

This routine switches the individual's characteristics from the temporary arrays to the original arrays.

USAGE:

CALL SWITCHFISH (parameters)

PARAMETER:

Male, Assign

Pop, NewFish, NumLoci, NewGeno, FPop, NewMale, NewAssign, Fish, FishGeno,

NORMAL EXITS: The arrays are successfully transferred.

SUBROUTINE: $\quad$ POPTEST

PURPOSE: The purpose of this routine is to test the male and the female populations, and the population as a whole for valid amounts of individuals to continue the simulation.

USAGE:

CALL POPTEST (parameters)

PARAMETERS: $\quad$ Pop, FPop, Multi, PS, ErrorFound

NORMAL EXITS: The populations are valid.

ERROR CONDITIONS: The populations are below the valid limits; in which, a message is written to the file PT_SN.DAT, at user request, and the error found indicator returns to the main program.

\section{SUBROUTINE: $\quad$ SORTGENOS}

PURPOSE: $\quad$ The purpose for this routine is to put the brood relation coefficients for fecundity selection, the sex frequencies for sexual selection, the allele frequencies for meiotic drive/gametic selection, the genotypes', betas, and frequencies for each locus in ascending order according to the genotypes' frequency.

USAGE:

CALL SORTGENOS (parameters)

PARAMETERS: NumGeno, GenoBetas, GenoFreq, GenoType, Loci, Selection, MAllele1, FAllele1, MAllele2, FAllele2, SSelection, SexChar, MSexFreq, FSexFreq, FLowerWgt, FUpperWgt, FSlope, FIntercept, FMaxBrood, FSelection, MSelection, MWgtLmt

NORMAL EXITS: All the genotypes, betas, and frequencies, etc. are correctly sorted in ascending order 
according to their frequencies.

III.

STRS_PRINT.FOR

SUBROUTINE:

PRINTRESULT

PURPOSE:

This routine calls PRINTCHAR to format and write the characteristics of each individual to the specified file as requested. Then the MTTD files are formatted and written, as requested.

USAGE:

CALL PRINTRESULT (parameters)

PARAMETERS: GO, GC, MO, MC, PS, Sim, Gen, S, Pop, Fish, FishGeno, NumLoci, NumGeno, GenoType, Multi, FPop, Male, Assign, LociLabel, Results, X, PageNum, Winter

NORMAL EXITS: The characteristics of each individual are written to the specified file.

SUBROUTINE: $\quad$ PRINTCHAR

PURPOSE: This routine formats and writes the characteristics of each individual to the specified file.

USAGE: $\quad$ CALL PRINTCHAR (parameters)

PARAMETERS: $\quad$ GO, GC, Sim, Gen, String, Ch, Ch2, Pop, Fish, FishGeno, NumLoci, NumGeno, GenoType, Multi, FPop, Male, Assign, LociLabel, Results, X, PageNum, Winter

NORMAL EXITS: The characteristics of each individual are written to the specified file.

SUBROUTINE: $\quad$ SUMMARYONE

PURPOSE: $\quad$ This routine is called by PRINTCHAR to sort and to determine the median weights (mg) of the female population and of the male population.

USAGE: $\quad$ CALL SUMMARYONE (parameters)

PARAMETERS: $\quad$ Pop, FPop, Fish, Wgts

NORMAL EXITS: The $25 \%, 50 \%$, and $75 \%$ medians of weight for sex are returned to PRINTCHAR.

SUBROUTINE: $\quad$ SUMMARYTWO

PURPOSE: This routine is called by PRINTCHAR to find the genotype frequencies for each locus for the current population. 
USAGE:

PARAMETERS:

NORMAL EXITS:

SUBROUTINE:

PURPOSE: $50 \%$, and $75 \%$ medians and returns these values to the main program.

USAGE:

PARAMETERS:

NORMAL EXITS:

CALL SUMMARYTWO (parameters)

SORTMTTD CALL SORTMTTD (parameters)

Fish, Pop, MTTD

The values above are found and returned.
NumGeno, NumLoci, Pop, FishGeno, GenoType, Freq

The frequencies are found and returned to PRINTCHAR.

This routine sorts the Median Times To Death of each individual and determines the $25 \%$, 
GEN_OUT.DAT: This file list the characteristics of each individual in the populations of any gestation period of any simulation. In this file the user is given the simulation and the gestation period numbers, the event (that is Before exposure, After exposure, and Final), the current population, and the current female population. This is followed by a list of all the characteristics if each individual (ID number, sex, size in mg, cumulative survival, median time-to-death, age in days, natural time-to-death, growth rate, the winter time-to-death, and the genotype for each of that individual's loci, and if that individual is female then the genotype for each locus belonging to the male assigned to that female is listed). Once the entire population for an event is listed, a summary is printed for that population. This summary contains the median weights for both males and females, and the frequencies for each genotype in each locus for that specific population.

GEN_CUT.DAT: This file is simply the cut version of GEN_OUT.DAT. However, this file only list simulation and gestation period numbers, the event (B, A, F), the population, ID number, sex, rounded size in mg, rounded median time-to-death, rounded age in days, rounded natural time-to-death, rounded winter time-to-death, and the genotypes for each locus. This file does not contain headings or summaries.

MTTD_OUT.DAT: This file outputs the median time-to-death for the $25 \%$, the $50 \%$, and the $75 \%$, for each event of each gestation period of each simulation.

MTTD_CUT.DAT: This file outputs the rounded median time-to-death for the $25 \%$, the $50 \%$, and the $75 \%$, for each event of each gestation period of each simulation. This file does not contain headings.

PT_SN.DAT: $\quad$ This file outputs simulation and gestation period numbers, event, male population, female population, entire population, $50 \%$ median time-to-death, and any messages (what appears on the screen during an interactive run of the program). 
MAIN PROGRAM: MAKE.For

PURPOSE: The purpose of this program is to create the data file for the batch routines to read. This file is converted from the data file read into the interactive routines.

INPUT: User's data file from interactive routines, and additional data entered interactively to create the new data file. (See Input Data File Format for Batch or the table of definitions at the end.)

OUTPUT: $\quad$ The new data file in the new format.

NORMAL EXITS: Completes process and saves new data file named STRS.DAT.

ERROR CONDITIONS: User's input data file cannot be found or the format of the user's input data file is incorrect.

SUBROUTINE: — SELECTOUTPUT

PURPOSE: This routine writes a menu of output files and their descriptions to the screen. The user is allowed to select the specific output files needed and the specific simulation and gestation periods for GEN_CUT.DAT and/or GEN_CUT.DAT.

USAGE:

CALL SELECTOUTPUT (parameters)

PARAMETERS: $\quad$ NumSim, NumGen, GO, GC, PS, MO, MC, N, Results

NORMAL EXITS: $\quad$ The user has selected the output files and simulations and gestation periods needed.

ERROR CONDITIONS: If the first number entered here is not the exact number of output files the user requests or if this number or any of the output file id numbers are not within their range, then an error message is written to the screen and the user is allowed to make corrections.

SUBROUTINE: $\quad$ TEST_RESULTS

PURPOSE: This routine is used only if the GEN_OUT or the GEN_CUT file is requested by the user. The simulations and gestation periods required for these files are tested and put in ascending order.

USAGE:

CALL TESTRESULTS (parameters)

PARAMETERS: $\quad$ N, Results

NORMAL EXITS: The data are data type integer and within the respective ranges.

ERROR CONDITIONS: If the above condition is not true, then an error message is written to the screen and user is allowed to make corrections. 


\begin{tabular}{|c|c|c|c|c|}
\hline Variable & Description & Where used & Range/format & Reference \\
\hline BASE & $\begin{array}{l}\text { Intercept parameter for accelerated } \\
\text { failure time model. }\end{array}$ & $\begin{array}{l}\text { Used in the subroutine CALC. } \\
\text { This is } \mu \text { in Equation } 3 \text {. } \\
\text { Entered manually or via data file. }\end{array}$ & $\begin{array}{l}\text { REAL } \\
\text { RANGE }(0.000 \text { TO } 100.000) \\
\text { FORMAT F11.5 }\end{array}$ & Diamond et al. ,1989 \\
\hline CMALES & $\begin{array}{l}\text { The maximum number of males } \\
\text { contributing sperm per female when } \\
\text { multiple insemination and sperm storage } \\
\text { occurs. }\end{array}$ & $\begin{array}{l}\text { Used in the subroutine SELECTGENO. } \\
\text { Entered manually or via data file. }\end{array}$ & $\begin{array}{l}\text { INTEGER } \\
\text { RANGE (1 TO 5) } \\
\text { FORMAT I5 }\end{array}$ & \\
\hline CNTLMT & $\begin{array}{l}\text { Maximum number of females a male can } \\
\text { inseminate during each gestation period. }\end{array}$ & $\begin{array}{l}\text { Used in the subroutine SELECTGENO. } \\
\text { Entered manually or via data file. }\end{array}$ & $\begin{array}{l}\text { INTEGER } \\
\text { RANGE (1 TO 1000) } \\
\text { FORMAT I5 }\end{array}$ & \\
\hline CSLOPE & $\begin{array}{l}\text { Slope coefficient for density and size- } \\
\text { dependent mortality. }\end{array}$ & $\begin{array}{l}\text { Used in the subroutine CANN. } \\
\text { See Equation } 10 . \\
\text { Entered manually or via data file. }\end{array}$ & $\begin{array}{l}\text { REAL } \\
\text { RANGE (-1.000 TO } 0.000) \\
\text { FORMAT F11.5 }\end{array}$ & \\
\hline DURATIONI & Initial exposure duration (in hours). & $\begin{array}{l}\text { Used in the subroutine CALC. } \\
\text { This is } t \text { in Equation } 5 \text {. } \\
\text { Entered manually or via data file. }\end{array}$ & $\begin{array}{l}\text { INTEGER } \\
\text { RANGE (0 TO } 1000 \text { HOURS) } \\
\text { FORMAT I5 }\end{array}$ & \\
\hline DURATION2 & Final exposure duration (in hours). & $\begin{array}{l}\text { Used in the subroutine CALC. } \\
\text { This is } t \text { in Equation } 5 \text {. } \\
\text { Entered manually or via data } \\
\text { file. }\end{array}$ & $\begin{array}{l}\text { INTEGER } \\
\text { RANGE (0 TO } 1000 \text { HOURS) } \\
\text { FORMAT I5 }\end{array}$ & \\
\hline EXPOSE & $\begin{array}{l}\text { Frequency of exposure (in gestation } \\
\text { periods). }\end{array}$ & $\begin{array}{l}\text { Used in the main program. } \\
\text { Entered manually or via data file. }\end{array}$ & $\begin{array}{l}\text { INTEGER } \\
\text { RANGE ( } 1 \text { TO } 5 \text { GESTATION } \\
\text { PERIODS) } \\
\text { FORMAT } 15\end{array}$ & \\
\hline FALLELE1 & $\begin{array}{l}\text { Probability of selection of first maternal } \\
\text { allele (used with meiotic drive/gametic } \\
\text { selection). }\end{array}$ & $\begin{array}{l}\text { Used in the subroutine SELECTGENO. } \\
\text { Entered manually or via data file. }\end{array}$ & $\begin{array}{l}\text { REAL } \\
\text { DIMENSION FALLELE1 }(20,6) \\
\text { RANGE }(0.00 \text { TO } 1.00) \\
\text { FORMAT F11.5 }\end{array}$ & \\
\hline FALLELE2 & $\begin{array}{l}\text { Probability of selection of second } \\
\text { maternal allele (used with meiotic } \\
\text { drive/gametic selection). }\end{array}$ & $\begin{array}{l}\text { Used in the subroutine SELECTGENO. } \\
\text { Entered manually or via data file. }\end{array}$ & $\begin{array}{l}\text { REAL } \\
\text { DIMENSION FALLELE2 }(20,6) \\
\text { RANGE }(0.00 \text { TO } 1.00) \\
\text { FORMAT F11.5 }\end{array}$ & \\
\hline
\end{tabular}




\begin{tabular}{|c|c|c|c|c|}
\hline Variable & Description & Where used & Range/format & Reference \\
\hline FBETA & $\begin{array}{l}\text { Female beta coefficient for natural } \\
\text { mortality routine. }\end{array}$ & $\begin{array}{l}\text { Used in the subroutines CREATE and } \\
\text { MORTALITY. } \\
\text { This is } \beta \text { in Equation } 2 \text {. } \\
\text { Entered manually or via data file. }\end{array}$ & $\begin{array}{l}\text { REAL } \\
\text { RANGE }(0.000 \text { TO } 300.000) \\
\text { FORMAT F11.5 }\end{array}$ & \\
\hline FGRM & Mean female growth rate. & $\begin{array}{l}\text { Used in the subroutine CREATE. } \\
\text { Entered manually or via data file. }\end{array}$ & $\begin{array}{l}\text { REAL } \\
\text { RANGE }(0.000 \text { TO 1.000) } \\
\text { FORMAT F11.5 }\end{array}$ & Mulvey et al. \\
\hline FGRSD & $\begin{array}{l}\text { Standard deviation of female growth } \\
\text { rate. }\end{array}$ & $\begin{array}{l}\text { Used in the subroutine CREATE. } \\
\text { Entered manually or via data file. }\end{array}$ & $\begin{array}{l}\text { REAL } \\
\text { RANGE }(0.000 \text { TO } 1.000) \\
\text { FORMAT F11.5 }\end{array}$ & Mulvey et al. \\
\hline FINTERCEPT & $\begin{array}{l}\text { Intercept parameter for maximum brood } \\
\text { size relation with fecundity selection. }\end{array}$ & $\begin{array}{l}\text { Used in the subroutine BROODSIZE. } \\
\text { See Equation } 8 \text {. } \\
\text { Entered manually or via data file. }\end{array}$ & $\begin{array}{l}\text { REAL } \\
\text { DIMENSION FINTERCEPT }(20,6) \\
\text { RANGE }(0.000 \text { TO 100.000) } \\
\text { FORMAT F11.5 } \\
\end{array}$ & Mulvey et al. \\
\hline FLOWERWGT & $\begin{array}{l}\text { Female's lower weight limit in mg (wet } \\
\text { mass), for brood relation with fecundity } \\
\text { selection. }\end{array}$ & $\begin{array}{l}\text { Used in the subroutine BROODSIZE. } \\
\text { Entered manually or via data file. }\end{array}$ & $\begin{array}{l}\text { REAL } \\
\text { DIMENSION FLOWERWGT(20,6) } \\
\text { RANGE (5.000 TO 5000.000 OF } \\
\text { WET MASS IN MG) } \\
\text { FORMAT F11.5 }\end{array}$ & Mulvey et al. \\
\hline FMAX & $\begin{array}{l}\text { Maximum weight in } \mathrm{mg} \text { (wet mass), for } \\
\text { a female. }\end{array}$ & $\begin{array}{l}\text { Used in the subroutine GROWTH } \\
\text { (within CREATEPOP) to assign an age } \\
\text { to each individual. This is } \mathrm{W}_{\max } \text { in } \\
\text { Equation } 1 . \\
\text { Entered manually or via data file. }\end{array}$ & $\begin{array}{l}\text { REAL } \\
\text { RANGE }(0.001 \text { TO } 5000.000 \mathrm{MG}) \\
\text { FORMAT F11.5 }\end{array}$ & Mulvey et al. \\
\hline FMAXBROOD & $\begin{array}{l}\text { Maximum number of newborns per } \\
\text { brood when fecundity selection is in } \\
\text { effect. }\end{array}$ & $\begin{array}{l}\text { Used in the subroutine BROODSIZE } \\
\text { Calculated in Equation } 7 \text {, then used in } \\
\text { Equation } 8 \text {. }\end{array}$ & $\begin{array}{l}\text { INTEGER } \\
\text { DIMENSION FMAXBROOD } \\
(20,6) \\
\text { RANGE (0 TO 100) }\end{array}$ & Mulvey et al. \\
\hline FMAXGEN & $\begin{array}{l}\text { Maximum number of gestation periods a } \\
\text { female can live. }\end{array}$ & $\begin{array}{l}\text { Used in the subroutines CREATE and } \\
\text { MORTALITY. } \\
\text { Entered manually or via data file. }\end{array}$ & $\begin{array}{l}\text { INTEGER } \\
\text { RANGE (1 TO 30) } \\
\text { FORMAT I5 }\end{array}$ & Krumholz, 1948 \\
\hline
\end{tabular}




\begin{tabular}{|c|c|c|c|c|}
\hline Variable & Description & Where used & Range/format & Reference \\
\hline FMEAN & $\begin{array}{l}\text { Mean of underlying distribution of size } \\
\text { of females. }\end{array}$ & $\begin{array}{l}\text { Used in the subroutine WEIGHTS } \\
\text { (within CREATEPOP) to assign a size to } \\
\text { each individual. Entered manually or via } \\
\text { data file. }\end{array}$ & $\begin{array}{l}\text { REAL } \\
\text { RANGE (0.001 TO 5.000) } \\
\text { FORMAT F11.5 }\end{array}$ & Mulvey et al. \\
\hline FMIN & $\begin{array}{l}\text { Minimum weight in mg (wet mass), for } \\
\text { a female. }\end{array}$ & $\begin{array}{l}\text { Used in the subroutine CREATE. } \\
\text { Entered manually or via data file. }\end{array}$ & $\begin{array}{l}\text { REAL } \\
\text { RANGE (0.001 TO } 5000.000 \text { MG) } \\
\text { FORMAT F11.5 }\end{array}$ & Mulvey et al. \\
\hline FORM & $\begin{array}{l}\text { Indicates whether the fish weights and } \\
\beta_{w} \text { have been log transformed. }\end{array}$ & $\begin{array}{l}\text { Used in the subroutine CALC. } \\
\text { Entered manually or via data file. }\end{array}$ & $\begin{array}{l}\text { LOGICAL } \\
\text { RANGE ('T' OR 'F') } \\
\text { FORMAT L }\end{array}$ & \\
\hline FSCALE & $\begin{array}{l}\text { Female scale coefficient for natural } \\
\text { mortality routine. }\end{array}$ & $\begin{array}{l}\text { Used in the subroutines CREATE and } \\
\text { MORTALITY. } \\
\text { This is SCALE in Equation } 2 . \\
\text { Entered manually or via data file. }\end{array}$ & $\begin{array}{l}\text { REAL } \\
\text { RANGE (0.000 TO 200.000) } \\
\text { FORMAT F11.5 }\end{array}$ & \\
\hline FSD & $\begin{array}{l}\text { Standard deviation of underlying } \\
\text { distribution of size of females. }\end{array}$ & $\begin{array}{l}\text { Used in the subroutine WEIGHTS } \\
\text { (within CREATEPOP) to assign a size to } \\
\text { each individual. Entered manually or via } \\
\text { data file. }\end{array}$ & $\begin{array}{l}\text { REAL } \\
\text { RANGE (0.001 TO 10.000) } \\
\text { FORMAT F11.5 }\end{array}$ & Mulvey et al. \\
\hline FSELECTION & $\begin{array}{l}\text { Indicates whether fecundity selection } \\
\text { selection occurs. }\end{array}$ & $\begin{array}{l}\text { Used in the subroutines MALELOCI and } \\
\text { BROODSIZE } \\
\text { Entered manually or via data file. }\end{array}$ & $\begin{array}{l}\text { LOGICAL } \\
\text { RANGE ('T' OR 'F') } \\
\text { FORMAT L }\end{array}$ & \\
\hline FSEXFREQ & $\begin{array}{l}\text { Array of female sexual selection } \\
\text { frequencies for each genotype. }\end{array}$ & $\begin{array}{l}\text { Used in the subroutine MALELOCI and } \\
\text { BROODSIZE. } \\
\text { Entered manually or via data file. }\end{array}$ & $\begin{array}{l}\text { REAL } \\
\text { DIMENSION FSEXFREQ }(20,6) \\
\text { RANGE }(0.00 \text { TO } 1.00) \\
\text { FORMAT F11.5 }\end{array}$ & \\
\hline FSHAPE & $\begin{array}{l}\text { Female shape parameter for growth } \\
\text { routine. }\end{array}$ & $\begin{array}{l}\text { Used in the subroutine CREATE. } \\
\text { This is SHAPE in Equation } 1 . \\
\text { Entered manually or via data file. }\end{array}$ & $\begin{array}{l}\text { REAL } \\
\text { RANGE }(0.00 \text { TO 6.00) } \\
\text { FORMAT F11.5 }\end{array}$ & \\
\hline FSLOPE & $\begin{array}{l}\text { Slope coefficient for maximum brood } \\
\text { size relation with fecundity selection. }\end{array}$ & $\begin{array}{l}\text { Used in the subroutine BROODSIZE. } \\
\text { See Equation } 8 \text {. } \\
\text { Entered manually or via data file. }\end{array}$ & $\begin{array}{l}\text { REAL } \\
\text { DIMENSION FSLOPE }(20,6) \\
\text { RANGE }(0.000 \text { TO } 1.000) \\
\text { FORMAT F11.5 }\end{array}$ & Mulvey et al. \\
\hline
\end{tabular}




\begin{tabular}{|c|c|c|c|c|}
\hline Variable & Description & Where used & Range/format & Reference \\
\hline FUPPERWGT & $\begin{array}{l}\text { Female's upper weight limit in } \mathrm{mg} \text { (wet } \\
\text { mass), for brood relation with fecundity } \\
\text { selection. }\end{array}$ & $\begin{array}{l}\text { Used in the subroutine BROODSIZE. } \\
\text { Entered manually or via data file. }\end{array}$ & $\begin{array}{l}\text { REAL } \\
\text { DIMENSION FUPPERWGT }(20,6) \\
\text { RANGE }(5.000 \text { TO } 5000.000 \text { OF } \\
\text { WET MASS IN MG) } \\
\text { FORMAT F11.5 }\end{array}$ & Mulvey et al. \\
\hline FWBETA & $\begin{array}{l}\text { Female beta coefficient for winter } \\
\text { mortality routine. }\end{array}$ & $\begin{array}{l}\text { Used in the subroutines CREATE and } \\
\text { MORTALITY. } \\
\text { This is } \beta \text { in Equation } 2 \text {. } \\
\text { Entered manually or via data file. }\end{array}$ & $\begin{array}{l}\text { REAL } \\
\text { RANGE }(0.000 \text { TO } 300.000) \\
\text { FORMAT F11.5 }\end{array}$ & \\
\hline FWHICHLOCI & $\begin{array}{l}\text { Indicates whether fecundity selection } \\
\text { occurs at each specific locus. }\end{array}$ & $\begin{array}{l}\text { Used in the subroutines MALELOCI and } \\
\text { BROODSIZE. } \\
\text { Entered manually or via data file. }\end{array}$ & $\begin{array}{l}\text { LOGICAL } \\
\text { DIMENSION FWHICHLOCI (20) } \\
\text { RANGE ('T' OR 'F') } \\
\text { FORMAT L }\end{array}$ & \\
\hline FWSCALE & $\begin{array}{l}\text { Female scale coefficient for winter } \\
\text { mortality routine. }\end{array}$ & $\begin{array}{l}\text { Used in the subroutines CREATE and } \\
\text { MORTALITY. } \\
\text { This is SCALE in Equation } 2 \text {. } \\
\text { Entered manually or via data file. }\end{array}$ & $\begin{array}{l}\text { REAL. } \\
\text { RANGE }(0.000 \text { TO } 200.000) \\
\text { FORMAT F11.5 }\end{array}$ & \\
\hline GENOBETAS & Array of betas for each genotype. & $\begin{array}{l}\text { Used in the subroutine CALC. This is } \beta_{g} \\
\text { in Equation } 3 \text {. } \\
\text { Entered manually or via data file. }\end{array}$ & $\begin{array}{l}\text { REAL } \\
\text { DIMENSION GENOBETAS }(20,6) \\
\text { RANGE }(0.000 \text { TO } 1.000) \\
\text { FORMAT F11.5 }\end{array}$ & Diamond et al., 1989) \\
\hline GENOFREQ & Array of frequencies of each genotype. & $\begin{array}{l}\text { Used in the subroutine GETGENO } \\
\text { (within CREATEPOP). } \\
\text { Entered manually or via data file. }\end{array}$ & $\begin{array}{l}\text { REAL } \\
\text { DIMENSION GENOFREQ }(20,6) \\
\text { RANGE }(-10.00 \text { TO 10.00) } \\
\text { FORMAT F11.5 }\end{array}$ & $\begin{array}{l}\text { Diamond et al., } 1989 \\
\text { Hernandez-Martich and Smith, } 1990 \\
\text { Newman et al., } 1989\end{array}$ \\
\hline GENOTYPE*2 & $\begin{array}{l}\text { Array of labels for genotypes at each } \\
\text { locus. }\end{array}$ & $\begin{array}{l}\text { Used in the subroutines CREATE and } \\
\text { CALC. } \\
\text { Entered manually or via data file. }\end{array}$ & $\begin{array}{l}\text { CHARACTER } \\
\text { DIMENSION GENOTYPE }(20,6) \\
\text { EXAMPLE: '11' } \\
\text { FORMAT A }\end{array}$ & \\
\hline GPT & $\begin{array}{l}\text { The gestation period in which the } \\
\text { toxicant exposure duration changes. }\end{array}$ & $\begin{array}{l}\text { Used in the main program. } \\
\text { Entered manually or via data file. }\end{array}$ & $\begin{array}{l}\text { INTEGER } \\
\text { RANGE (1 TO 10000) } \\
\text { FORMAT I5 }\end{array}$ & \\
\hline IMMPOP & $\begin{array}{l}\text { Number of individuals migrating into the } \\
\text { population each gestation period. }\end{array}$ & $\begin{array}{l}\text { Used in the main program to simulate } \\
\text { migration. Entered manually. }\end{array}$ & $\begin{array}{l}\text { INTEGER } \\
\text { RANGE (0 TO 10000) }\end{array}$ & \\
\hline
\end{tabular}




\begin{tabular}{|c|c|c|c|c|}
\hline Variable & Description & Where used & Range/format & Reference \\
\hline INITPOP & $\begin{array}{l}\text { Number of individuals in the initial } \\
\text { simulated population. }\end{array}$ & $\begin{array}{l}\text { Used in the main program to set up the } \\
\text { initial population. Entered manually. }\end{array}$ & $\begin{array}{l}\text { INTEGER } \\
\text { RANGE (2 TO 10000) }\end{array}$ & \\
\hline INTERCEPT & $\begin{array}{l}\text { Intercept parameter for maximum brood } \\
\text { size relation. }\end{array}$ & $\begin{array}{l}\text { Used in the subroutine BROODSIZE. } \\
\text { See Equation } 8 \text {. } \\
\text { Entered manually or via data file. }\end{array}$ & $\begin{array}{l}\text { REAL } \\
\text { RANGE }(0.000 \text { TO } 100.000) \\
\text { FORMAT F11.5 }\end{array}$ & Mulvey et al. \\
\hline 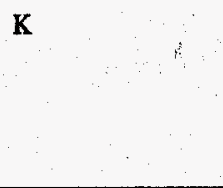 & The population carrying capacity. & $\begin{array}{l}\text { Used in the subroutines SELECTGENO, } \\
\text { BROODSIZE, MORTALITY, and } \\
\text { CANN. } \\
\text { See Equation } 9 \text {. } \\
\text { Entered manually or via data file. }\end{array}$ & $\begin{array}{l}\text { NTTEGER } \\
\text { RANGE (1 TO 10000) } \\
\text { FORMAT } 15\end{array}$ & \\
\hline LENGEN & $\begin{array}{l}\text { The number of days in one gestation } \\
\text { period. }\end{array}$ & $\begin{array}{l}\text { Used in the subroutines CREATE, } \\
\text { MORTALITY, BROODSIZE, and } \\
\text { GROWTH. } \\
\text { Entered manually or via data file. }\end{array}$ & $\begin{array}{l}\text { REAL } \\
\text { RANGE ( } 14.000 \text { TO } 42.000 \text { DAYS) } \\
\text { FORMAT F11.5 }\end{array}$ & Krumholz, 1948 \\
\hline LOCILABEL*10 & Array of names for each locus. & $\begin{array}{l}\text { Used in output. } \\
\text { Entered manually or via data file. }\end{array}$ & $\begin{array}{l}\text { CHARACTER } \\
\text { DIMENSION LOCILABEL (20) } \\
\text { EXAMPLE: 'ICD-1' } \\
\text { FORMAT A }\end{array}$ & \\
\hline LONGEVITY & $\begin{array}{l}\text { Parameter used in natural mortality } \\
\text { caculation. }\end{array}$ & $\begin{array}{l}\text { Used in the subroutine MORTALITY. } \\
\text { See Equation } 7 . \\
\text { Entered manually or via data file. }\end{array}$ & $\begin{array}{l}\text { REAL } \\
\text { RANGE }(0.0 \text { TO 1.0) } \\
\text { FORMAT F11.5 }\end{array}$ & \\
\hline LOWERWGT & $\begin{array}{l}\text { Female's lower weight limit in } \mathrm{mg} \text { (wet } \\
\text { mass) for brood relation. }\end{array}$ & $\begin{array}{l}\text { Used in the subroutine BROODSIZE. } \\
\text { Entered manually or via data file. }\end{array}$ & $\begin{array}{l}\text { REAL } \\
\text { RANGE (5.000 TO } 5000.000 \text { OF } \\
\text { WET MASS IN MG) } \\
\text { FORMAT F11.5 }\end{array}$ & Mulvey et al. \\
\hline MALEFREQ & $\begin{array}{l}\text { Array of probabilities of each possible } \\
\text { number of males insemenating a female. }\end{array}$ & $\begin{array}{l}\text { Used in the subroutine SELECTGENO. } \\
\text { Entered manually or via data file. }\end{array}$ & $\begin{array}{l}\text { REAL } \\
\text { DIMENSION MALEFREQ (5) } \\
\text { RANGE }(0.000 \text { TO } 1.000) \\
\text { FORMAT F11.5 }\end{array}$ & \\
\hline MALLELE1 & $\begin{array}{l}\text { Probability of selection of first paternal } \\
\text { allele (used with meiotic drive/gametic } \\
\text { selection). }\end{array}$ & $\begin{array}{l}\text { Used in the subroutine SELECTGENO. } \\
\text { Entered manually or via data file. }\end{array}$ & $\begin{array}{l}\text { REAL } \\
\text { DIMENSION MALLELE1 }(20,6) \\
\text { RANGE }(0.00 \text { TO } 1.00) \\
\text { FORMAT F11.5 }\end{array}$ & \\
\hline
\end{tabular}




\begin{tabular}{|c|c|c|c|c|}
\hline Variable & Description & Where used & Range/format & Reference \\
\hline MALLELE2 & $\begin{array}{l}\text { Probability of selection of second } \\
\text { patemal allele (used with meiotic } \\
\text { drive/gametic selection). }\end{array}$ & $\begin{array}{l}\text { Used in the subroutine SELECTGENO. } \\
\text { Entered manually or via data file. }\end{array}$ & $\begin{array}{l}\text { REAL } \\
\text { DIMENSION MALLELE2 }(20,6) \\
\text { RANGE }(0.00 \text { TO } 1.00) \\
\text { FORMAT F11.5 }\end{array}$ & \\
\hline MAXBROOD & $\begin{array}{l}\text { Maximum number of newborns per } \\
\text { brood. }\end{array}$ & $\begin{array}{l}\text { Used in the subroutine BROODSIZE. } \\
\text { Calculated in Equation } 8 \text {, then used in } \\
\text { Equation } 9 .\end{array}$ & $\begin{array}{l}\text { INTEGER } \\
\text { RANGE (0 TO 100) }\end{array}$ & Mulvey et al. \\
\hline MAXC & $\begin{array}{l}\text { Maximum probability for density and } \\
\text { size-dependent mortality. }\end{array}$ & $\begin{array}{l}\text { Used in the subroutine CANN. } \\
\text { See Equation } 10 \text {. } \\
\text { Entered manually or via data file. }\end{array}$ & $\begin{array}{l}\text { REAL } \\
\text { RANGE (0.000 TO 1.000) } \\
\text { FORMAT F11.5 } \\
\end{array}$ & \\
\hline MBETA & $\begin{array}{l}\text { Male beta coefficient for natural } \\
\text { mortality routine. }\end{array}$ & $\begin{array}{l}\text { Used in the subroutines CREATE and } \\
\text { MORTALITY. } \\
\text { This is } \beta \text { in Equation } 2 \text {. } \\
\text { Entered manually or via data file. }\end{array}$ & $\begin{array}{l}\text { REAL } \\
\text { RANGE }(0.000 \text { TO } 300.000) \\
\text { FORMAT F11.5 }\end{array}$ & : \\
\hline MGRM & Mean male growth rate. & $\begin{array}{l}\text { Used in the subroutine CREATE. } \\
\text { Entered manually or via data file. }\end{array}$ & $\begin{array}{l}\text { REAL } \\
\text { RANGE }(0.000 \text { TO } 1.000) \\
\text { FORMAT F11.5 } \\
\end{array}$ & Mulvey et al. \\
\hline MGRSD & Standard deviation of male growth rate. & $\begin{array}{l}\text { Used in the subroutine CREATE. } \\
\text { Entered manually or via data file. }\end{array}$ & $\begin{array}{l}\text { REAL } \\
\text { RANGE }(0.000 \text { TO } 1.000) \\
\text { FORMAT F11.5 }\end{array}$ & Mulvey et al. \\
\hline MMAX & $\begin{array}{l}\text { Maximum weight in } \mathrm{mg} \text { (wet mass), for } \\
\text { a male. }\end{array}$ & $\begin{array}{l}\text { Used in the subroutine GROWTH } \\
\text { (within CREATEPOP) to assign an age } \\
\text { to each individual. This is } W_{\max } \text { in } \\
\text { Equation } 1 . \\
\text { Entered manually or via data file. }\end{array}$ & $\begin{array}{l}\text { REAL } \\
\text { RANGE (0.001 TO } 5000.000 \mathrm{MG}) \\
\text { FORMAT F11.5 }\end{array}$ & Mulvey et al. \\
\hline MMAXGEN & $\begin{array}{l}\text { Maximum number of gestation periods a } \\
\text { male can live. }\end{array}$ & $\begin{array}{l}\text { Used in the subroutines CREATE and } \\
\text { MORTALITY. } \\
\text { Entered manually or via data file. }\end{array}$ & $\begin{array}{l}\text { INTEGER } \\
\text { RANGE ( } 1 \text { TO 30) } \\
\text { FORMAT I5 }\end{array}$ & Krumholz, 1948 \\
\hline MMEAN & $\begin{array}{l}\text { Mean of underlying distribution of size } \\
\text { of males. }\end{array}$ & $\begin{array}{l}\text { Used in the subroutine WEIGHTS } \\
\text { (within CREATEPOP) to assign a size to } \\
\text { each individual. Entered manually or via } \\
\text { data file. }\end{array}$ & $\begin{array}{l}\text { REAL } \\
\text { RANGE (0.001 TO 5.000) } \\
\text { FORMAT F11.5 }\end{array}$ & Mulvey et al. \\
\hline
\end{tabular}




\begin{tabular}{|c|c|c|c|c|}
\hline Variable & Description & Where used & Range/format & Reference \\
\hline MMIN , & $\begin{array}{l}\text { Minimum weight in mg (wet mass), for } \\
\text { a male. }\end{array}$ & $\begin{array}{l}\text { Used in the subroutine CREATE. } \\
\text { Entered manually or via data file. }\end{array}$ & $\begin{array}{l}\text { REAL } \\
\text { RANGE (0.001 TO } 5000.000 \mathrm{MG}) \\
\text { FORMAT F11.5 }\end{array}$ & Mulvey et al. \\
\hline MSCALE & $\begin{array}{l}\text { Male scale coefficient for natural } \\
\text { mortality routine. }\end{array}$ & $\begin{array}{l}\text { Used in the subroutines CREATE and } \\
\text { MORTALITY. } \\
\text { This is SCALE in Equation } 2 . \\
\text { Entered manually or via data file. }\end{array}$ & $\begin{array}{l}\text { REAL } \\
\text { RANGE }(0.000 \text { TO 200.000) } \\
\text { FORMAT F11.5 }\end{array}$ & \\
\hline MSD & $\begin{array}{l}\text { Standard deviation of underlying } \\
\text { distribution of size of males. }\end{array}$ & $\begin{array}{l}\text { Used in the subroutine WEIGHTS } \\
\text { (within CREATEPOP) to assign a size to } \\
\text { each individual. Entered manually or via } \\
\text { data file. }\end{array}$ & $\begin{array}{l}\text { REAL } \\
\text { RANGE }(0.001 \text { TO 10.000) } \\
\text { FORMAT F11.5 }\end{array}$ & Mulvey et al. \\
\hline MSELECTION & $\begin{array}{l}\text { Indicates whether male weight limit } \\
\text { selection occurs. }\end{array}$ & $\begin{array}{l}\text { Used in the subroutines MALELOCI . } \\
\text { Entered manually or via data file. }\end{array}$ & $\begin{array}{l}\text { LOGICAL } \\
\text { RANGE ('T' OR 'F') } \\
\text { FORMAT L }\end{array}$ & \\
\hline MSEXFREQ & $\begin{array}{l}\text { Array of male sexual selection } \\
\text { frequencies for each genotype. }\end{array}$ & $\begin{array}{l}\text { Used in the subroutine MALELOCI. } \\
\text { Entered manually or via data file. }\end{array}$ & $\begin{array}{l}\text { REAL } \\
\text { DIMENSION MSEXFREQ }(20,6) \\
\text { RANGE }(0.00 \text { TO } 1.00) \\
\text { FORMAT F11.5 }\end{array}$ & \\
\hline MSHAPE & Male shape factor for growth routine. & $\begin{array}{l}\text { Used in the subroutine CREATE. } \\
\text { This is SHAPE in Equation } 1 . \\
\text { Entered manually or via data file. }\end{array}$ & $\begin{array}{l}\text { REAL } \\
\text { RANGE (0.00 TO 6.00) } \\
\text { FORMAT F11.5 }\end{array}$ & \\
\hline MULTI & $\begin{array}{l}\text { Indicates whether multiple insemination } \\
\text { and sperm storage occur. }\end{array}$ & $\begin{array}{l}\text { Used in the main program. } \\
\text { Entered manually or via data file. }\end{array}$ & $\begin{array}{l}\text { LOGICAL } \\
\text { RANGE ('T' OR 'F') } \\
\text { FORMAT L } \\
\end{array}$ & \\
\hline MWBETA & $\begin{array}{l}\text { Male beta coefficient for winter } \\
\text { mortality routine. }\end{array}$ & $\begin{array}{l}\text { Used in the subroutines CREATE and } \\
\text { MORTALITY. } \\
\text { This is } \beta \text { in Equation } 2 \text {. } \\
\text { Entered manually or via data file. }\end{array}$ & $\begin{array}{l}\text { REAL } \\
\text { RANGE }(0.000 \text { TO } 300.000) \\
\text { FORMAT F11.5 }\end{array}$ & \\
\hline MWGTLMT & $\begin{array}{l}\text { Array of male weight limits for each } \\
\text { genotype ( used with male weight limit } \\
\text { selection). }\end{array}$ & $\begin{array}{l}\text { Used in the subroutine MALELOCI. } \\
\text { Entered manually or via data file. }\end{array}$ & $\begin{array}{l}\text { REAL } \\
\text { DIMENSION MWGTLMT }(20,6) \\
\text { RANGE }(0.001 \text { TO 5000.000) } \\
\text { FORMAT F11.5 }\end{array}$ & \\
\hline
\end{tabular}




\begin{tabular}{|c|c|c|c|c|}
\hline Variable & Description & Where used & Range/format & Reference \\
\hline MWHICHLOCI & $\begin{array}{l}\text { Indicates whether weight limit selection } \\
\text { occurs at each particular male locus. }\end{array}$ & $\begin{array}{l}\text { Used in the subroutines MALELOCI . } \\
\text { Entered manually or via data file. }\end{array}$ & $\begin{array}{l}\text { LOGICAL } \\
\text { DIMENSION MWHICHLOCI (20) } \\
\text { RANGE ('T' OR 'F') } \\
\text { FORMAT L } \\
\end{array}$ & \\
\hline MWSCALE & $\begin{array}{l}\text { Male scale coefficient for winter } \\
\text { mortality routine. }\end{array}$ & $\begin{array}{l}\text { Used in the subroutines CREATE and } \\
\text { MORTALITY. } \\
\text { This is SCALE in Equation } 2 \text {. } \\
\text { Entered manually or via data file. }\end{array}$ & $\begin{array}{l}\text { REAL } \\
\text { RANGE }(0.000 \text { TO 200.000) } \\
\text { FORMAT F11.5 }\end{array}$ & \\
\hline NUMGEN & $\begin{array}{l}\text { The number of gestation periods per } \\
\text { simulation }\end{array}$ & $\begin{array}{l}\text { Used in the main program gestation } \\
\text { period loop. Entered manually. }\end{array}$ & $\begin{array}{l}\text { INTEGER } \\
\text { RANGE (1 TO 10000) }\end{array}$ & \\
\hline NUMGENO & The number of genotypes per locus. & $\begin{array}{l}\text { Used in the subroutine CREATE. } \\
\text { Entered manually or via data file. Also } \\
\text { used as a delimiter throughout the } \\
\text { program routines. }\end{array}$ & $\begin{array}{l}\text { INTEGER } \\
\text { DIMENSION NUMGENO (20) } \\
\text { RANGE (3 OR 6) } \\
\text { FORMAT I5 } \\
\end{array}$ & \\
\hline NUMLOCI & The number of loci. & $\begin{array}{l}\text { Used in the subroutine CREATE. } \\
\text { Entered manually or via data file. Also } \\
\text { used as a delimiter throughout the } \\
\text { program routines. }\end{array}$ & $\begin{array}{l}\text { INTEGER } \\
\text { RANGE (0 TO 20) } \\
\text { FORMAT I5 }\end{array}$ & \\
\hline NUMSIM & $\begin{array}{l}\text { The number of simulations to be } \\
\text { processed. }\end{array}$ & $\begin{array}{l}\text { Used in the main program simulation } \\
\text { loop. Entered manually. }\end{array}$ & $\begin{array}{l}\text { INTEGER } \\
\text { RANGE (1 TO 10000) }\end{array}$ & \\
\hline PDF & $\begin{array}{l}\text { Indicates whether fish weights are } \\
\text { normally distributed. }\end{array}$ & $\begin{array}{l}\text { Used in the subroutine CREATE. } \\
\text { Entered manually or via data file. }\end{array}$ & $\begin{array}{l}\text { LOGICAL } \\
\text { RANGE ('T' OR 'F') } \\
\text { FORMAT L }\end{array}$ & \\
\hline REFGENO*2 & $\begin{array}{l}\text { Array of reference genotypes for each } \\
\text { locus. }\end{array}$ & $\begin{array}{l}\text { Used in the subroutines CREATE and } \\
\text { CALC. } \\
\text { Entered manually or via data file. }\end{array}$ & $\begin{array}{l}\text { CHARACTER } \\
\text { DIMENSION REFGENO (20) } \\
\text { EXAMPLE: ' } 11 \text { ' } \\
\text { FORMAT A }\end{array}$ & \\
\hline REFSEX & Indicates the reference sex. & $\begin{array}{l}\text { Used in the subroutines CREATE and } \\
\text { CALC. } \\
\text { Entered manually or via data file. }\end{array}$ & $\begin{array}{l}\text { CHARACTER } \\
\text { RANGE ('F' OR 'M') } \\
\text { FORMAT A }\end{array}$ & \\
\hline SCALE & $\begin{array}{l}\text { Scale coefficient for accelerated failure } \\
\text { time model. }\end{array}$ & $\begin{array}{l}\text { Used in the subroutine CALC. } \\
\text { This is } \sigma \text { in Equation } 3 . \\
\text { Entered manually or via data file. }\end{array}$ & $\begin{array}{l}\text { REAL } \\
\text { RANGE }(0.000 \text { TO } 100.000) \\
\text { FORMAT F11.5 }\end{array}$ & Diamond et al., 1989FSELECTION \\
\hline
\end{tabular}




\begin{tabular}{|c|c|c|c|c|}
\hline Variable & Description & Where used & Range/format & Reference \\
\hline SELECTION & $\begin{array}{l}\text { Indicates whether meiotic drive/gametic } \\
\text { selection occurs. }\end{array}$ & $\begin{array}{l}\text { Used in the subroutines SELECTGENO. } \\
\text { Entered manually or vi data file. }\end{array}$ & $\begin{array}{l}\text { LOGICAL } \\
\text { RANGE ('T' OR 'F') } \\
\text { FORMAT L }\end{array}$ & FSELECTION \\
\hline SEXBETA & Beta coefficient for sex. & $\begin{array}{l}\text { Used in the subroutine CALC in the } \\
\text { calculation of XBETA. See } \beta_{8} \text { below } \\
\text { Equation } 3 \text {. } \\
\text { Entered manually or via data file. }\end{array}$ & $\begin{array}{l}\text { REAL } \\
\text { RANGE (-10.00 TO 10.00) } \\
\text { FORMAT F11.5 }\end{array}$ & Diamond et al., 1989 \\
\hline SEXCHAR & $\begin{array}{l}\text { Indicates whether sexual selection occurs } \\
\text { at each locus for male /female/both. }\end{array}$ & $\begin{array}{l}\text { Used in the subroutines MALELOCI and } \\
\text { BROODSIZE. } \\
\text { Entered manually or via data file. }\end{array}$ & $\begin{array}{l}\text { CHARACTER } \\
\text { DIMENSION SEXCHAR (20) } \\
\text { RANGE (M/F/B) } \\
\text { FORMAT A }\end{array}$ & \\
\hline SEXRATIO & $\begin{array}{l}\text { Percentage of individuals of the } \\
\text { reference sex in the population. }\end{array}$ & $\begin{array}{l}\text { Used in the subroutine ASSIGNSEX } \\
\text { (within CREATEPOP). } \\
\text { Entered manually or via data file. }\end{array}$ & $\begin{array}{l}\text { REAL } \\
\text { RANGE }(0.00 \text { TO } 1.00) \\
\text { FORMAT F11.5 }\end{array}$ & \\
\hline SHIFT & $\begin{array}{l}\text { The median shift: } \exp (\epsilon) \text { in Equation 3; } \\
0.693147 \text { for Weibull distribution. }\end{array}$ & $\begin{array}{l}\text { Used in the subroutine CALC. } \\
\text { Entered manually or via data } \\
\text { file. }\end{array}$ & $\begin{array}{l}\text { REAL } \\
\text { RANGE (-10.000 TO } 10.000) \\
\text { FORMAT F11.5 }\end{array}$ & \\
\hline SIZEBETA & Beta coefficient for size. & $\begin{array}{l}\text { Used in the subroutine CALC in the } \\
\text { calculation of XBETA. See } \beta_{w} \text { below } \\
\text { Equation } 3 \text {. } \\
\text { Entered manually or via data file. }\end{array}$ & $\begin{array}{l}\text { REAL } \\
\text { RANGE }(0.00 \text { TO } 100.00) \\
\text { FORMAT F11.5 }\end{array}$ & Diamond et al., 1989 \\
\hline SLOPE & $\begin{array}{l}\text { Slope coefficient for maximum brood } \\
\text { size relation. }\end{array}$ & $\begin{array}{l}\text { Used in the subroutine BROODSIZE. } \\
\text { See Equation } 8 \text {. } \\
\text { Entered manually or via data file. }\end{array}$ & $\begin{array}{l}\text { REAL } \\
\text { RANGE (0.000 TO 1.000) } \\
\text { FORMAT F11.5 }\end{array}$ & \\
\hline SSELECTION & $\begin{array}{l}\text { Indicates whether sexual selection } \\
\text { occurs. }\end{array}$ & $\begin{array}{l}\text { Used in the subroutines MALELOCI and } \\
\text { BROODSIZE. } \\
\text { Entered manually or via data file. }\end{array}$ & $\begin{array}{l}\text { LOGICAL } \\
\text { RANGE ('T' OR 'F') } \\
\text { FORMAT L }\end{array}$ & \\
\hline UPPERWGT & $\begin{array}{l}\text { Female upper weight limit in } \mathrm{mg} \text { (wet } \\
\text { mass), for brood relation. }\end{array}$ & $\begin{array}{l}\text { Used in the subroutine BROODSIZE. } \\
\text { Entered manually or via data file. }\end{array}$ & $\begin{array}{l}\text { REAL } \\
\text { RANGE (5.000 TO } 5000.000 \text { OF } \\
\text { WET MASS IN MG) } \\
\text { FORMAT F11.5 }\end{array}$ & \\
\hline WD & Duration of winter (in gestation periods). & $\begin{array}{l}\text { Used in the main program. } \\
\text { Entered manually or via data file. }\end{array}$ & $\begin{array}{l}\text { INTEGER } \\
\text { RANGE (0 TO 15) } \\
\text { FORMAT I5 }\end{array}$ & \\
\hline
\end{tabular}




\begin{tabular}{|c|c|c|c|c|}
\hline Variable & Description & Where used & Range/format & Reference \\
\hline WGTLMT & $\begin{array}{l}\text { Lower weight limit in mg (wet mass), } \\
\text { for a breeding male. }\end{array}$ & $\begin{array}{l}\text { Used in the subroutine SELECTGENO. } \\
\text { Entered manually or via data file. }\end{array}$ & $\begin{array}{l}\text { REAL } \\
\text { RANGE (0.001 TO } 5000.000 \mathrm{MG)} \\
\text { (FOR SELECTGENO) } \\
\text { FORMAT F11.5 } \\
\end{array}$ & \\
\hline WHICHLOCI & $\begin{array}{l}\text { Indicates whether sexual selection occurs } \\
\text { at each particular locus. }\end{array}$ & $\begin{array}{l}\text { Used in the subroutines MALELOCI and } \\
\text { BROODSIZE. } \\
\text { Entered manually or via data file. }\end{array}$ & $\begin{array}{l}\text { LOGICAL } \\
\text { DIMENSION WHICHLOCI (20) } \\
\text { RANGE ('T' OR 'F') } \\
\text { FORMAT L } \\
\end{array}$ & \\
\hline WIMMPOP & $\begin{array}{l}\text { Number of individuals migrating into the } \\
\text { population each winter gestation period. }\end{array}$ & $\begin{array}{l}\text { Used in the main program to simulate } \\
\text { migration during winter. Entered } \\
\text { manually. }\end{array}$ & $\begin{array}{l}\text { INTEGER } \\
\text { RANGE (0 TO 10000) }\end{array}$ & \\
\hline ww & $\begin{array}{l}\text { Frequency of winter (in gestation } \\
\text { periods). }\end{array}$ & $\begin{array}{l}\text { Used in the main program. } \\
\text { Entered manually or via data file. }\end{array}$ & $\begin{array}{l}\text { INTEGER } \\
\text { RANGE (0 TO 15) } \\
\text { FORMAT I5 }\end{array}$ & \\
\hline
\end{tabular}


Input Data File Format :

\begin{tabular}{|c|c|c|c|c|c|}
\hline $\begin{array}{l}\text { NumLoci } \\
15\end{array}$ & $\begin{array}{l}\text { Selection } \\
\mathrm{L}\end{array}$ & $\begin{array}{l}\text { SSelection } \\
\mathrm{L}\end{array}$ & $\begin{array}{l}\text { FSelection } \\
\text { L }\end{array}$ & $\begin{array}{l}\text { MSelection } \\
\text { L }\end{array}$ & \\
\hline $\begin{array}{l}\text { LociLabel } \\
A^{* 10}\end{array}$ & $\begin{array}{l}\text { NumGeno } \\
\text { I5 }\end{array}$ & $\begin{array}{l}\text { RefGeno } \\
A * 2\end{array}$ & & & \\
\hline $\begin{array}{l}\text { WhichLoci } \\
\text { L }\end{array}$ & $\begin{array}{l}\text { FWhichLoci } \\
\text { L }\end{array}$ & $\begin{array}{l}\text { MWhichLoci } \\
\text { L }\end{array}$ & & & \\
\hline \multicolumn{6}{|l|}{$\begin{array}{l}\text { SexChar } \\
\text { A }\end{array}$} \\
\hline $\begin{array}{l}\text { GenoType } \\
A * 2\end{array}$ & $\begin{array}{l}\text { GenoFreq } \\
\text { F11.5 }\end{array}$ & $\begin{array}{l}\text { GenoBeta } \\
\text { F11.5 }\end{array}$ & & & \\
\hline $\begin{array}{l}\text { MAllele1 } \\
\text { F11.5 }\end{array}$ & \begin{tabular}{|l|} 
FAllele1 \\
F11.5 \\
\end{tabular} & $\begin{array}{l}\text { MAllele2 } \\
\text { F11.5 }\end{array}$ & $\begin{array}{l}\text { FAllele2 } \\
\text { F11.5 }\end{array}$ & & \\
\hline $\begin{array}{l}\text { MSexFreq } \\
\text { F11.5 }\end{array}$ & $\begin{array}{l}\text { FSexFreq } \\
\text { F11.5 }\end{array}$ & & & & \\
\hline $\begin{array}{l}\text { FUpperWgt } \\
\text { F11.5 }\end{array}$ & $\begin{array}{l}\text { FLowerWgt } \\
\text { F11.5 }\end{array}$ & $\begin{array}{l}\text { FSlope } \\
\text { F11.5 }\end{array}$ & $\begin{array}{l}\text { FIntercept } \\
\text { F11.5 }\end{array}$ & & \\
\hline \multicolumn{6}{|l|}{$\begin{array}{l}\text { MWgtLmt } \\
\text { F11.5 }\end{array}$} \\
\hline $\begin{array}{l}\text { MBeta } \\
\text { F11.5 }\end{array}$ & $\begin{array}{l}\text { FBeta } \\
\text { F11.5 }\end{array}$ & $\begin{array}{l}\text { MScale } \\
\text { F11.5 }\end{array}$ & $\begin{array}{l}\text { FScale } \\
\text { F11.5 }\end{array}$ & & \\
\hline $\begin{array}{l}\text { Longevity } \\
\text { F11.5 }\end{array}$ & $\begin{array}{l}\text { MMaxGen } \\
\text { I5 }\end{array}$ & $\begin{array}{l}\text { FMaxGen } \\
15\end{array}$ & & & \\
\hline $\begin{array}{l}\text { MWBeta } \\
\text { F11.5 }\end{array}$ & $\begin{array}{l}\text { FWBeta } \\
\text { F11.5 }\end{array}$ & $\begin{array}{l}\text { MWScale } \\
\text { F11.5 }\end{array}$ & $\begin{array}{l}\text { FWScale } \\
\text { F11.5 }\end{array}$ & $\begin{array}{l}\text { WW } \\
\text { I5 }\end{array}$ & $\begin{array}{l}\text { WD } \\
\text { I5 }\end{array}$ \\
\hline $\begin{array}{l}\text { MMean } \\
\text { F11.5 }\end{array}$ & $\begin{array}{l}\text { FMean } \\
\text { F11.5 }\end{array}$ & $\begin{array}{l}\text { MSD } \\
\text { F11.5 }\end{array}$ & $\begin{array}{l}\text { FSD } \\
\text { F11.5 }\end{array}$ & $\begin{array}{l}\text { PDF } \\
\text { L }\end{array}$ & \\
\hline $\begin{array}{l}\text { MMax } \\
\text { F11.5 }\end{array}$ & $\begin{array}{l}\text { FMax } \\
\text { F11.5 }\end{array}$ & $\begin{array}{l}\text { MMin } \\
\text { F11.5 }\end{array}$ & $\begin{array}{l}\text { FMin } \\
\text { F11.5 }\end{array}$ & & \\
\hline $\begin{array}{l}\text { MGRM } \\
\text { F11.5 }\end{array}$ & $\begin{array}{l}\text { FGRM } \\
\text { F11.5 }\end{array}$ & $\begin{array}{l}\text { MGRSD } \\
\text { F11.5 }\end{array}$ & $\begin{array}{l}\text { FGRSD } \\
\text { F11.5 }\end{array}$ & & \\
\hline $\begin{array}{l}\text { MShape } \\
\text { F11.5 }\end{array}$ & $\begin{array}{l}\text { FShape } \\
\text { F11.5 }\end{array}$ & $\begin{array}{l}\text { Base } \\
\text { F11.5 }\end{array}$ & $\begin{array}{l}\text { Scale } \\
\text { F11.5 }\end{array}$ & $\begin{array}{l}\text { Duration 1 } \\
\text { I5 }\end{array}$ & $\begin{array}{l}\text { Duration2 } \\
\text { I5 }\end{array}$ \\
\hline $\begin{array}{l}\text { GPt } \\
\text { I5 }\end{array}$ & $\begin{array}{l}\text { Shift } \\
\text { F11.5 }\end{array}$ & \begin{tabular}{|l} 
SizeBeta \\
F11.5
\end{tabular} & $\begin{array}{l}\text { SexBeta } \\
\text { F11.5 }\end{array}$ & $\begin{array}{l}\text { Form } \\
\text { L }\end{array}$ & $\begin{array}{l}\text { Expose } \\
\text { I5 }\end{array}$ \\
\hline $\begin{array}{l}K \\
\text { I5 }\end{array}$ & $\begin{array}{l}\text { WgtLmt } \\
\text { F11.5 }\end{array}$ & $\begin{array}{l}\text { CntLmt } \\
\text { I5 }\end{array}$ & & & \\
\hline $\begin{array}{l}\text { UpperWgt } \\
\text { F11.5 }\end{array}$ & $\begin{array}{l}\text { LowerWgt } \\
\text { F11.5 }\end{array}$ & $\begin{array}{l}\text { Slope } \\
\text { F11.5 }\end{array}$ & $\begin{array}{l}\text { Intercept } \\
\text { F11.5 }\end{array}$ & & \\
\hline $\begin{array}{l}\text { MaxC } \\
\text { F11.5 }\end{array}$ & $\begin{array}{l}\text { CSlope } \\
\text { F11.5 }\end{array}$ & & & & \\
\hline
\end{tabular}




\begin{tabular}{|l|l|l|l|l|l|}
\hline $\begin{array}{l}\text { Multi } \\
\text { L }\end{array}$ & $\begin{array}{l}\text { CMales } \\
\text { I5 }\end{array}$ & & & & \\
\hline $\begin{array}{l}\text { MaleFreq } \\
\text { F11.5 }\end{array}$ & & & & & \\
\hline $\begin{array}{l}\text { RefSex } \\
\text { A }\end{array}$ & $\begin{array}{l}\text { SexRatio } \\
\text { F11.5 }\end{array}$ & $\begin{array}{l}\text { LenGen } \\
\text { F11.5 }\end{array}$ & & & \\
\hline
\end{tabular}

Additional Input Data File Format for Batch Routine:

\begin{tabular}{|l|l|l|l|l|l||}
\hline $\begin{array}{l}\text { InitPop } \\
\text { I5 }\end{array}$ & $\begin{array}{l}\text { ImmPop } \\
\text { I5 }\end{array}$ & $\begin{array}{l}\text { WImmPop } \\
\text { I5 }\end{array}$ & & & \\
\hline $\begin{array}{l}\text { NumSim } \\
\text { I5 }\end{array}$ & $\begin{array}{l}\text { NumGen } \\
\text { I5 }\end{array}$ & & & & \\
\hline $\begin{array}{l}\text { GO } \\
\text { L }\end{array}$ & $\begin{array}{l}\text { GC } \\
\text { L }\end{array}$ & $\begin{array}{l}\text { MO } \\
\text { L }\end{array}$ & $\begin{array}{l}\text { MC } \\
\text { L }\end{array}$ & $\begin{array}{l}\text { PS } \\
\text { L }\end{array}$ & \\
\hline $\begin{array}{l}\text { NumOut } \\
\text { I5 }\end{array}$ & $\begin{array}{l}\text { SelectOut } \\
\text { I5 }\end{array}$ & & & & \\
\hline $\begin{array}{l}\text { SimNum } \\
\text { I5 }\end{array}$ & $\begin{array}{l}\text { GenNum } \\
\text { I5 }\end{array}$ & & & & \\
\hline
\end{tabular}


Fish and NewFish arrays :

\begin{tabular}{|c|c|c|}
\hline & Id \# & \\
\hline 1 & Sex & based on the sex ratio entered by the user \\
\hline 2 & Size & $\begin{array}{l}\text { weight in mg (wet mass), initially selected randomly, based on the } \\
\text { mean, standard deviation, and the pdf entered by the user; then is } \\
\text { incremented based on the growth rate, } \# 7\end{array}$ \\
\hline 3 & Cumulative Survival & $\begin{array}{l}\text { calculated and assigned every gestation period, using the sex beta, } \\
\text { size beta, form of size beta, the median shift, and the hazard } \\
\text { model slope and intercept entered by the user }\end{array}$ \\
\hline 4 & $\begin{array}{l}\text { Median Time-to- } \\
\text { death }\end{array}$ & $\begin{array}{l}\text { calculated and assigned every gestation period, using the sex beta, } \\
\text { size beta, form of size beta, the median shift, and the hazard } \\
\text { model slope and intercept entered by the user }\end{array}$ \\
\hline 5 & Age & $\begin{array}{l}\text { based on size, and incremented every gestation period by the } \\
\text { length of a gestation period entered by the user }\end{array}$ \\
\hline 6 & $\begin{array}{l}\text { Natural Time-to- } \\
\text { death }\end{array}$ & $\begin{array}{l}\text { time-to-death by natural cause assigned at birth, based on the betas } \\
\text { and scale factors entered by the user }\end{array}$ \\
\hline 7 & Growth Rate & $\begin{array}{l}\text { selected randomly, based on the mean and standard deviation } \\
\text { entered by the user }\end{array}$ \\
\hline 8 & $\begin{array}{l}\text { Winter Time-to- } \\
\text { death }\end{array}$ & $\begin{array}{l}\text { time-to-death by natural cause during winter gestation periods } \\
\text { assigned at birth, based on the betas and scale factors entered by } \\
\text { the user }\end{array}$ \\
\hline
\end{tabular}




\section{EXAMPLE:}

The following example contains one locus of six genotypes with selection. However, there is no meiotic drive/gametic selection, fecundity selection, sexual selection, or male weight selection occurring. The program ran for two simulations of 50 gestation periods each. The initial population was 750 individuals with no migration. There was no winter specified in this example and the number of hours of toxicant exposure was zero. All possible output files were requested. However, only a sample of Gen_out.dat and Gen Cut.dat were listed in this example.

The following file, STRS.dat, is the initial input file for the batch routines. This file can easily be modified to run with the interactive routines by deleting the last five lines of data which specify the initial population, migrating population, migrating population during winter, number of simulations, number of gestation periods, and outputs requested by the user.

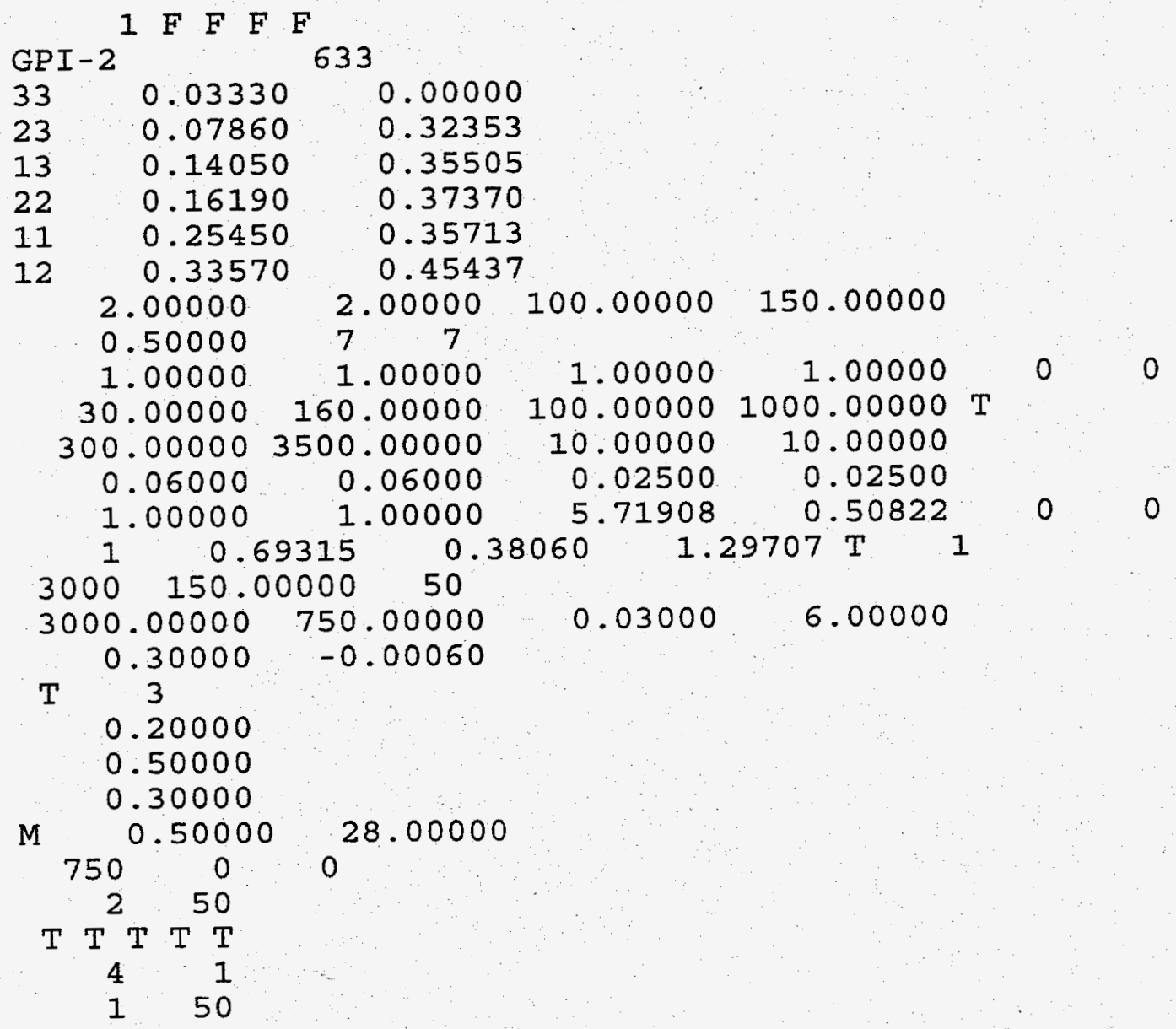


INITIAL INFORMATION

\begin{tabular}{|c|c|c|c|c|c|}
\hline \multirow{3}{*}{\multicolumn{5}{|c|}{ 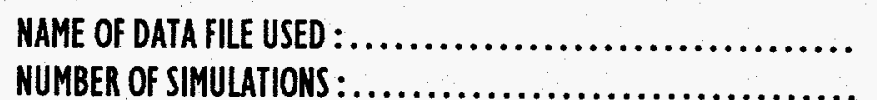 }} & \\
\hline & & & & & \\
\hline & & & & & \\
\hline \multicolumn{5}{|c|}{ 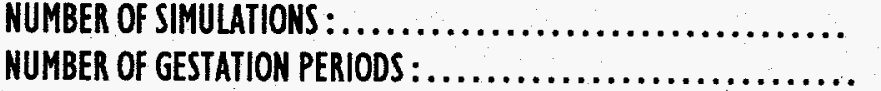 } & \\
\hline \multicolumn{5}{|c|}{ 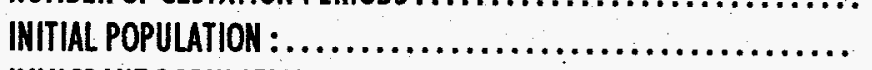 } & . \\
\hline \multicolumn{5}{|c|}{ 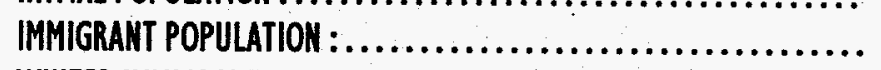 } & \\
\hline \multicolumn{5}{|c|}{ WINTER IMMIGRANT POPULATION : } & \\
\hline \multicolumn{5}{|c|}{ 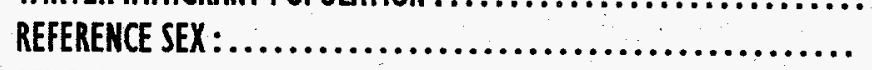 } & \\
\hline \multicolumn{5}{|c|}{ SEX RATIO: } & 0.500 \\
\hline \multicolumn{5}{|c|}{ 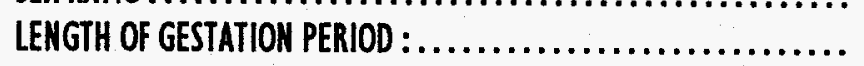 } & \\
\hline \multicolumn{6}{|c|}{ LOCUS CHARACTERISTICS } \\
\hline \multicolumn{5}{|c|}{ NUMBER Of $\mathrm{LOCl}$ :..... } & \\
\hline & NUMBER & REFERENCE & GENOTYPE & GENOTYPE & GENOTYPE \\
\hline LOCI LABEL & GENOTYPES & GENOTYPE & LABEL & FREQUENCY & BET \\
\hline \multirow[t]{6}{*}{ GPI-2 } & 6 & 33 & 33 & 0.03330 & 0.00000 \\
\hline & & & 23 & 60 & 0.32353 \\
\hline & & & 13 & 0.14050 & 0.35505 \\
\hline & & & 22 & 0.16190 & 0.37370 \\
\hline & & & II & & 0.35713 \\
\hline & & & 12 & 0.33570 & 0.454 \\
\hline
\end{tabular}

NO MEIOTIC DRIVE/GAMETIC SELECTION

NO SEXUAL SELECTION

NO FECUNDITY 


\section{NATURAL MORTALITY FACTORS}

MALE BETA $: \ldots \ldots 2.00000 \quad$ FEMALE BETA $: \ldots \ldots 2.00000$

MALE SCALE : .... 100.00000 FEMALE SCALE : ... 150.00000 MALE MAXIMUM PERIOOS OF GESTATION: ..... 7 FEMALE MAXIMUM PERIODS OF PROPORTIONAL LONGEVITY : 0.50000

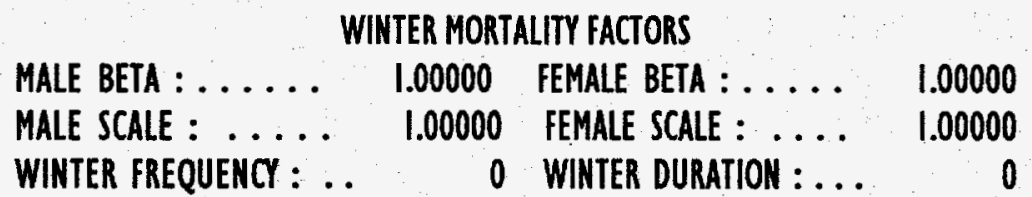

\begin{tabular}{|c|c|c|c|}
\hline & GROWTH AN & IZE FACTORS & \\
\hline MALE MAXIMUM & & FEMALE MAXIMUM & \\
\hline WEIGHT : & 300.00000 & WEIGHT : . & 3500.00000 \\
\hline MALE MINIMUM & & FEMALE MINIMUM & \\
\hline WEIGHT : & 10.00000 & WEIGHT : & 10.00000 \\
\hline MALE GROWTH RATE & & FEMALE GROWTH RATE & \\
\hline MEAN & 0.06000 & MEAN : & 0.06000 \\
\hline MALE GROWTH RATE & & FEMALE GROWTH RATE & \\
\hline MALE MEAN WEIGHT: & 30.00000 & FEMALE MEAN WEIGHT & 160.00000 \\
\hline MALE STANDARD DEVIA & & FEMALE STANDARD DE & IATION \\
\hline $\begin{array}{l}\text { WEIGHT : . . . } \\
\text { PROBILITY DENSITY }\end{array}$ & 100.00000 & WEIGHT & 1000.00 \\
\hline FUNCTIC & ) & & \\
\hline
\end{tabular}

\begin{tabular}{|c|c|c|c|}
\hline \multirow{2}{*}{\multicolumn{4}{|c|}{ EXPOSURE COEFFICIENTS }} \\
\hline & & & \\
\hline & 1 & INTERCEPT : & 5.71908 \\
\hline HAZARD MODEL SCALE & & DURATION OF EXPOSURE I & \\
\hline PARAMETER : & 0.50822 & (HOURS) : & \\
\hline DURATION OF EXPOSURE 2 & & CHANGE DURATION AT & \\
\hline UURSS : & 0 & GESTATION PERIOD : . & \\
\hline E BETÁ: & 1.29707 & SEX BETA: & 0.380 \\
\hline Taucran & JGNORMAL & MENUAN SHIET & 69 \\
\hline
\end{tabular}

CANMIBALISM COEFFICIENTS

MAXIMUM $: \ldots \ldots, 0.30000 \quad$ SLOPE $: \ldots \ldots \ldots,-0.00060$ 


\section{BREEDING AND BROOD RELATION COEFFICIENTS}

MINIMUM WEIGHT FOR A

MALE TO BREED : .. 150.00000

UPPER WEIGHT LIMIT : . 3000.00000

SLOPE

0.03000

3000
MAXIMUM NUMBER OF FEMALES

PER MALE : .... $\quad 50$

LOWER WEIGHT LIMIT : . 750.00000

INTERCEPT : ..... 6.00000

MAXIMUM BROOD SIZE : . $\quad 96$

MULTIPLE INSEMINATION AND SPERM STORAGE OCCURS

POSSIBLE 3 MALES CONTRIBUTING.

$\begin{array}{cc}\text { NUMBER FREQUENC } \\ 1 & .20000 \\ 2 & .50000 \\ 3 & 30000\end{array}$




\begin{tabular}{|c|c|c|c|c|c|c|}
\hline MULAT & ON \# & & 1 & & $O$ HOURS O & XPOSURE \\
\hline $\sin$ & GE & & TOTAL & MALES & FEMALES & MTTD \\
\hline 1 & I & B & 750 & 375 & 375 & 103.835 \\
\hline 1 & 2 & B & |381 & 667 & 714 & 56.425 \\
\hline 1 & 3 & B & 2324 & 1106 & 1218 & 66.949 \\
\hline 1 & 4 & B & 1832 & 775 & 1057 & 111.672 \\
\hline 1 & 5 & B & 3006 & 1327 & 1679 & 70.118 \\
\hline 1 & 6 & $B$ & 1395 & 491 & 904 & 130.588 \\
\hline 1 & 7 & & 5394 & 2500 & 2894 & 58.535 \\
\hline 1 & 8 & B & 2729 & 1026 & 1703 & 125.055 \\
\hline 1 & 9 & $B$ & 2148 & 726 & 1422 & 161.388 \\
\hline 1 & 10 & 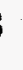 & 5824 & 2588 & 3236 & 56.905 \\
\hline 1 & II & 3 & 2455 & 884 & 1571 & 128.710 \\
\hline 1 & 12 & 3 & 3073 & 1165 & 1908 & 87.904 \\
\hline 1 & 13 & 3 & 1355 & 427 & 928 & 146.014 \\
\hline 1 & 14 & 3 & 9729 & 4556 & 5173 & 51.574 \\
\hline 1 & 15 & 3 & 4310 & 1646 & 2664 & 120.873 \\
\hline 1 & 16 & 3 & 2045 & 521 & 1524 & 264.108 \\
\hline 1 & 17 & & 10100 & 4572 & 5528 & 55.804 \\
\hline 1 & 18 & 8 & 4200 & 1535 & 2665 & 124.6 \\
\hline
\end{tabular}




\begin{tabular}{|c|c|c|c|c|c|c|}
\hline 1 & 19 & B & 1913 & 462 & $|45|$ & 277.925 \\
\hline 1 & 20 & B & 11151 & 5062 & 6089 & 54.295 \\
\hline & 21 & B & 4748 & 1809 & 2939 & 121.468 \\
\hline & 22 & B & 2231 & 556 & 1675 & 265.584 \\
\hline & 23 & B & 8524 & 3756 & 4768 & 57.585 \\
\hline & 24 & B & 3438 & 1279 & 2159 & 127.945 \\
\hline & 25 & B & $157 \mid$ & 404 & 1167 & 291.697 \\
\hline I & 26 & B & 12345 & 5763 & 6582 & 54.724 \\
\hline 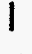 & 27 & B & 5302 & 2028 & 3274 & 121.982 \\
\hline I & 28 & B & 2444 & 595 & 1849 & 259.425 \\
\hline 1 & 29 & B & 5808 & 2375 & 3433 & 59.558 \\
\hline 1 & 30 & B & 2896 & 1113 & 1783 & 120.949 \\
\hline 1 & 31 & B & 1612 & 518 & 1094 & 182.037 \\
\hline 1 & 32 & B & 9552 & 4428 & 5124 & 55.770 \\
\hline I & 33 & B & 3939 & 1470 & 2469 & 128.880 \\
\hline 1 & 34 & B & 1778 & 430 & 1348 & 277.896 \\
\hline 1 & 35 & B & 11244 & 5157 & 6087 & 56.266 \\
\hline I & 36 & B & 4626 & 1672 & 2954 & 129.938 \\
\hline$I$ & 37 & B & 2103 & 480 & 1623 & 297.526 \\
\hline 1 & 38 & B & 9801 & 4366 & 5435 & 55.778 \\
\hline 1 & 39 & B & 4117 & $|50|$ & 2616 & 126.829 \\
\hline I & 40 & B & 1903 & 453 & 1450 & 277.739 \\
\hline 1 & 41 & $B$ & 11186 & 5105 & 6081 & 55.939 \\
\hline
\end{tabular}




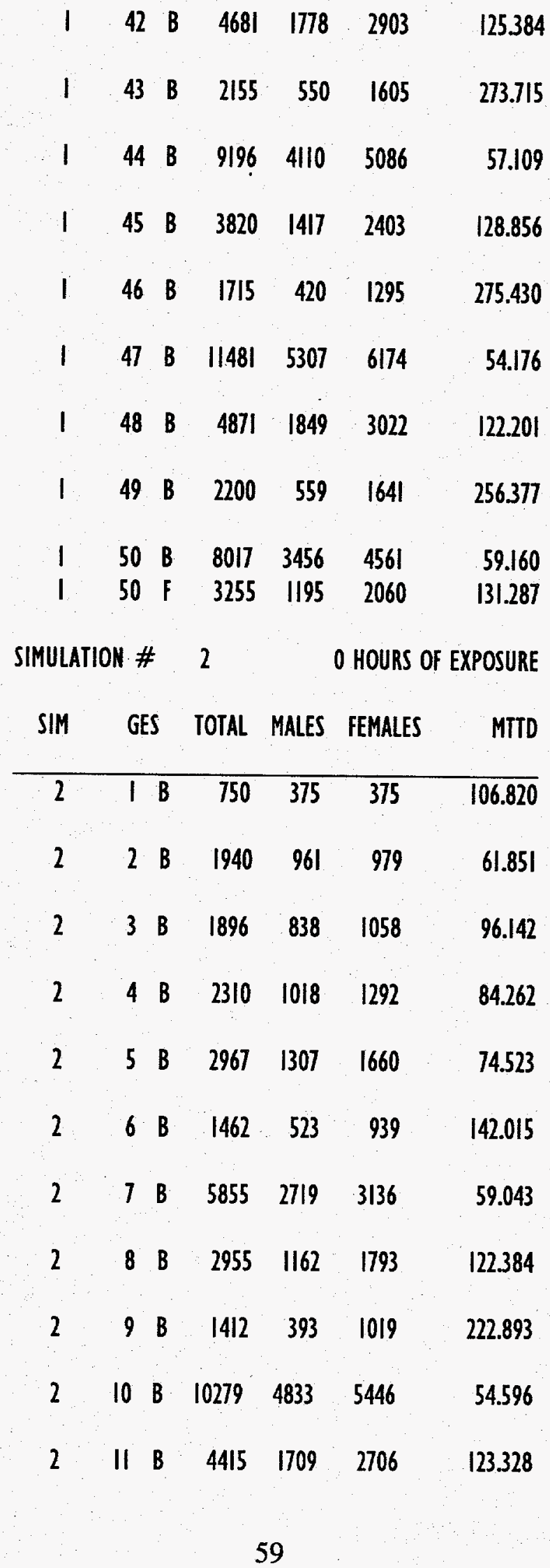




\begin{tabular}{|c|c|c|c|c|c|c|}
\hline 2 & 121 & B & 2069 & 522 & 1547 & 273.808 \\
\hline 2 & 13 & B & 9429 & 4199 & 5230 & 56.218 \\
\hline 2 & 14 & B & 3843 & $143 \mid$ & 2412 & 126.102 \\
\hline 2 & 15 & B & 1793 & $4 I I$ & 1382 & 292.734 \\
\hline 2 & 16 & $B$ & 12066 & 5504 & 6562 & 55.166 \\
\hline 2 & 17 & B & 5138 & 1919 & 3219 & 126395 \\
\hline 2 & 18 & B & 2395 & 618 & 1777 & 275.257 \\
\hline 2 & 191 & B & 6361 & 2674 & 3687 & 59.634 \\
\hline 2 & 20 & B & 2537 & 903 & 1634 & 131.279 \\
\hline 2 & 218 & B & 3050 & 1136 & 1914 & 94.725 \\
\hline 2 & 22 & B & 1310 & 402 & 908 & 157316 \\
\hline 2 & $23 \mathrm{~B}$ & B & 8972 & 4228 & 4744 & 55.420 \\
\hline 2 & 24 & B & 3798 & 1420 & 2378 & 126.651 \\
\hline 2 & 25 & B & 1748 & 425 & 1323 & 274.639 \\
\hline 2 & $26 \mathrm{~B}$ & B & 11850 & 5490 & 6360 & 55.390 \\
\hline 2 & 27 & B & 5033 & 1862 & 3171 & 126.210 \\
\hline 2 & 28 & B & 2296 & 575 & |721 & 266.030 \\
\hline 2 & 29 & B & 7271 & 3110 & $4|6|$ & 59.979 \\
\hline 2 & 30 & $B$ & 2937 & 1043 & 1894 & 131.876 \\
\hline 2 & 31 & B & 1610 & 449 & 1161 & 215347 \\
\hline 2 & 32 & B & 11562 & 5430 & 6132 & 55.604 \\
\hline 2 & 33 & B & 4982 & 1868 & 3114 & 124.653 \\
\hline 2 & 34 & B & 2294 & 577 & 1717 & 269.572 \\
\hline
\end{tabular}


$\begin{array}{lllllll}2 & 35 & \text { B } & 7550 & 3256 & 4294 & 57.582\end{array}$

$\begin{array}{lllllll}2 & 36 & \text { B } & 3080 & 1155 & 1925 & 128.448\end{array}$

$\begin{array}{lllllll}2 & 37 & \text { B } & 1328 & 330 & 998 & 284.498\end{array}$

$\begin{array}{llllllll}2 & 38 & \text { B } & 11232 & 5271 & 5961 & 55.329\end{array}$

$\begin{array}{lllllll}2 & 39 & B & 4835 & 1875 & 2960 & 126.381\end{array}$

$\begin{array}{llllllll}2 & 40 & \text { B } & 2191 & 570 & 1621 & 270.942\end{array}$

$\begin{array}{lllllll}2 & 41 & \text { B } & 8773 & 3860 & 4913 & 57.146\end{array}$

$\begin{array}{lllllll}2 & 42 & \text { B } & 3628 & 1326 & 2302 & 126.688\end{array}$

$\begin{array}{llllllll}2 & 43 & \text { B } & 1625 & 375 & 1250 & 293.173\end{array}$

$\begin{array}{lllllll}2 & 44 & \text { B } & 11807 & 5465 & 6342 & 54.419\end{array}$

$\begin{array}{llllllll}2 & 45 & 8 & 5151 & 1965 & 3186 & 125.916\end{array}$

$\begin{array}{lllllll}2 & 46 & \text { B } & 2337 & 598 & 1739 & 268.977\end{array}$

$\begin{array}{lllllll}2 & 47 & \text { B } & 6755 & 2875 & 3880 & 60.073\end{array}$

$\begin{array}{lllllll}2 & 48 & \text { B } & 2711 & 969 & 1742 & 130.419\end{array}$

$\begin{array}{lllllll}2 & 49 & \text { B } & 2433 & 850 & 1583 & 144.139\end{array}$

$\begin{array}{lllllll}2 & 50 & \text { B } & 4042 & 1704 & 2338 & 63.904\end{array}$

$\begin{array}{llllllll}2 & 50 & F & 1990 & 727 & 1263 & 129.627\end{array}$

.... PROGRAM RUN COMPLETE. 


\section{MTTD OUT.DAT}

\section{MEDIAN TIME TO DEATH}

\begin{tabular}{|c|c|c|c|c|}
\hline GESTATION & POPULATION & MTTD 25\% & MTTD 50\% & MTTD 75\% \\
\hline I BEFORE & 750 & 55.8394 & 103.8354 & 197.6312 \\
\hline 2 BEFORE & |38| & 41.0152 & 56.4249 & 98.7818 \\
\hline 3 BEFORE & 2324 & 45.5073 & 66.9488 & |14.594| \\
\hline 4 BEFORE & 1832 & 68.0203 & III.6724 & 182.4610 \\
\hline 5 BEFORE & 3006 & 45.3835 & 70.1179 & 170.5849 \\
\hline 6 BEFORE & 1395 & 82.7165 & 130.5884 & 229.2500 \\
\hline 7 BEFORE & 5394 & 42.5551 & 58.5348 & 99.2569 \\
\hline 8 BEFORE & 2729 & 84.4783 & 125.0550 & 195.1087 \\
\hline 9. BEFORE & 2148 & 66.0207 & 161.3879 & 394.3001 \\
\hline IO BEFORE & 5824 & 42.0160 & 56.9048 & 99.8174 \\
\hline II BEFORE & 2455 & 86.0721 & 128.7102 & 222.1350 \\
\hline I2 BEFORE & 3073 & 49.2842 & 87.9039 & 302.1966 \\
\hline I3 BEFORE & 1355 & 91.8123 & 146.0142 & 348.6466 \\
\hline I4 BEFORE & 9729 & 39.8495 & 51.5738 & 753638 \\
\hline I5 BEFORE & 4310 & 81.5424 & 120.8734 & 195.3799 \\
\hline
\end{tabular}




\begin{tabular}{|c|c|c|c|c|}
\hline 16 BEFORE & 2045 & 148.0736 & 264.1085 & 562.8987 \\
\hline I7 BEFORE & 10100 & 41.9207 & 55.8042 & 88.6062 \\
\hline I8 BEFORE & 4200 & 85.0089 & 124.6341 & 202.9312 \\
\hline 19 BEFORE & 1913 & 157.5053 & 277.9254 & 552.6414 \\
\hline 20 BEFORE & ||$|5|$ & 41.1047 & 54.2946 & 83.3606 \\
\hline 21 BEFORE & 4748 & 81.8303 & 121.4678 & 195.4674 \\
\hline 22 BEFORE & 2231 & 148.9612 & 265.5838 & 556.8875 \\
\hline 23 BEFORE & 8524 & 42.7203 & 57.5851 & 94.9057 \\
\hline 24 BEFORE & 3438 & 84.8305 & $127.945 \mid$ & 205.2758 \\
\hline 25 BEFORE & $157 \mid$ & 153.3463 & 291.6966 & 567.9891 \\
\hline 26 BEFORE & 12345 & 41.6587 & 54.7238 & 79.9644 \\
\hline 27 BEFORE & 5302 & 84.5721 & 121.9825 & 192.1638 \\
\hline 28 BEFORE & 2444 & 151.9784 & 259.4246 & 557.7822 \\
\hline 29 BEFORE & 5808 & 43.2139 & 59.5585 & 133.9016 \\
\hline 30 BEFORE & 2896 & 83.0387 & $|20.949|$ & 197.9897 \\
\hline 3I BEFORE & 1612 & 111.4936 & 182.0366 & 454.5093 \\
\hline 32 BEFORE & 9552 & 42.4791 & 55.7702 & 83.7519 \\
\hline 33 BEFORE & 3939 & 86.8559 & 128.8802 & 203.1264 \\
\hline 34 BEFORE & 1778 & 159.9235 & 277.8959 & 557.8219 \\
\hline 35 BEFORE & 11244 & 42.8576 & 56.2662 & 85.4687 \\
\hline 36 BEFORE & 4626 & 87.0710 & 129.9383 & 209.2869 \\
\hline 37 BEFORE & 2103 & 162.7050 & 297.5257 & 565.3935 \\
\hline 38 BEFORE & 9801 & 42.5120 & 55.7779 & 88.3340 \\
\hline
\end{tabular}




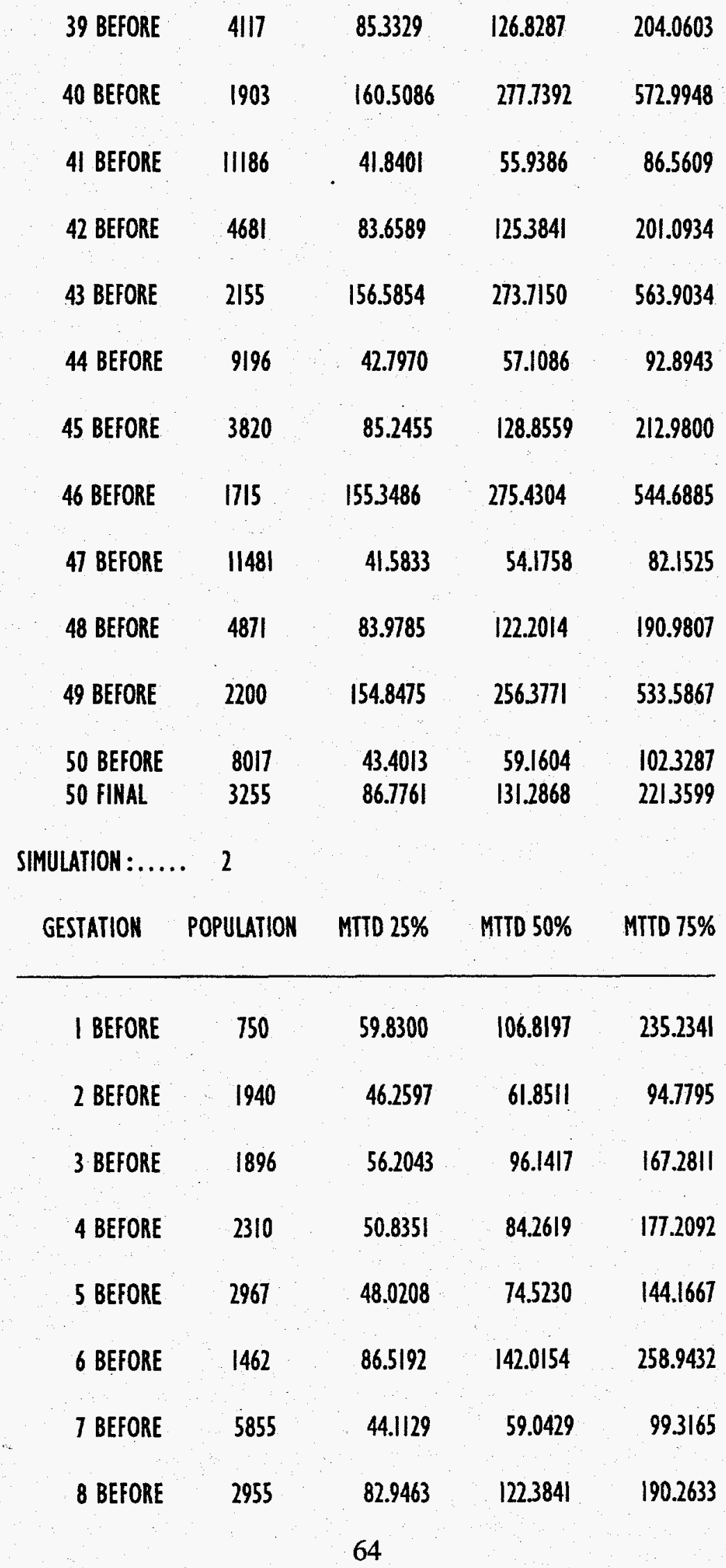




\begin{tabular}{|c|c|c|c|c|}
\hline 9 BEFORE & 1412 & 142.2506 & 222.8929 & 514.1082 \\
\hline IO BEFORE & 10279 & 41.6207 & 54.5965 & 80.0004 \\
\hline II BEFORE & 4415 & 82.4774 & 123.3280 & 193.4029 \\
\hline I2 BEFORE & 2069 & 154.5059 & 273.8084 & 551.6699 \\
\hline I3 BEFORE & 9429 & 42.3868 & 56.2176 & 92.1136 \\
\hline I4 BEFORE & 3843 & 85.2245 & 126.1015 & 207.8440 \\
\hline I5 BEFORE & 1793 & 156.3165 & 292.7345 & 591.0576 \\
\hline I6 BEFORE & 12066 & 41.9767 & 55.1660 & 82.4105 \\
\hline 17 BEFORE & 5138 & 84.4020 & 126.3951 & 198.6854 \\
\hline 18. BEFORE & 2395 & 155.0889 & 275.2566 & 549.0350 \\
\hline 19 BEFORE & 6361 & 43.2692 & 59.6345 & 120.7706 \\
\hline 20 BEFORE & 2537 & 87.4162 & 131.2789 & 219.7211 \\
\hline 2I BEFORE & 3050 & 53.5517 & 94.7253 & 305.1295 \\
\hline 22 BEFORE & 1310 & 98.1192 & 157.3159 & 365.2402 \\
\hline 23 BEFORE & 8972 & 42.5951 & 55.4196 & 82.3556 \\
\hline 24 BEFORE & 3798 & 85.7326 & 126.6508 & 199.8373 \\
\hline 25 BEFORE & 1748 & 157.2906 & 274.6386 & 567.9128 \\
\hline 26 BEFORE & 11850 & 41.8804 & 55.3898 & 84.5170 \\
\hline 27 BEFORE & 5033 & 83.6622 & 126.2102 & 198.4177 \\
\hline 28 BEFORE & 2296 & 155.5609 & 266.0305 & 550.0037 \\
\hline 29 BEFORE & 7271 & 43.8776 & 59.9785 & 105.5946 \\
\hline 30 BEFORE & 2937 & 87.4350 & $|3| .876 \mid$ & 218.5056 \\
\hline 3। BEFORE & 1610 & 124.8226 & 215.3469 & 534.9467 \\
\hline
\end{tabular}




\begin{tabular}{|c|c|c|c|c|}
\hline 32 BEFORE & 11562 & 42.1734 & 55.6041 & 82.0475 \\
\hline 33 BEFORE & 4982 & 84.6663 & 124.6530 & 197.5867 \\
\hline 34 BEFORE & 2294 & 154.1063 & 269.5715 & 557.3779 \\
\hline 35 BEFORE & 7550 & 42.8526 & 57.5816 & 100.5354 \\
\hline 36 BEFORE & 3080 & 84.2837 & 128.4477 & 215.2456 \\
\hline 37 BEFORE & 1328 & 155.4617 & 284.4980 & 550.5299 \\
\hline 38 BEFORE & 11232 & 42.5191 & 55.3287 & 81.7490 \\
\hline 39 BEFORE & 4835 & 84.8717 & 126.3813 & 202.0520 \\
\hline 40 BEFORE & $2|9|$ & 154.2947 & 270.9424 & 568.7601 \\
\hline 4I BEFORE & 8773 & 42.9952 & 57.1461 & 95.1977 \\
\hline 42 BEFORE & 3628 & 86.8830 & 126.6876 & 204.8461 \\
\hline 43 BEFORE & 1625 & 158.6203 & 293.1734 & 560.4737 \\
\hline 44 BEFORE & 11807 & 41.6371 & 54.4188 & 80.9102 \\
\hline 45 BEFORE & $5|5|$ & 85.4060 & 125.9157 & 196.4492 \\
\hline 46 BEFORE & 2337 & 156.9981 & 268.9773 & 549.1364 \\
\hline 47 BEFORE & 6755 & 44.3988 & 60.0734 & 114.4737 \\
\hline 48 BEFORE & 2711 & 89.2976 & 130.4189 & 226.9448 \\
\hline 49 BEFORE & 2433 & 61.0281 & 144.1389 & 395.4994 \\
\hline 50 BEFORE & 4042 & 45.1158 & 63.9042 & 135.3406 \\
\hline 50 FINAL & 1990 & 86.7195 & 129.6270 & 213.3209 \\
\hline
\end{tabular}




\begin{tabular}{|c|c|c|c|c|}
\hline $1 B$ & 750 & 56 & 104 & 198 \\
\hline $2 B$ & 1381 & 41 & 56 & 99 \\
\hline $3 B$ & 2324 & 46 & 67 & 115 \\
\hline $4 B$ & 1832 & 68 & 112 & 182 \\
\hline $5 B$ & 3006 & 45 & 70 & 171 \\
\hline $6 \mathrm{~B}$ & 1395 & 83 & $|3|$ & 229 \\
\hline $7 B$ & 5394 & 43 & 59 & 99 \\
\hline $8 B$ & 2729 & 84 & 125 & 195 \\
\hline $9 B$ & 2148 & 66 & 161 & 394 \\
\hline $10 \mathrm{~B}$ & 5824 & 42 & 57 & 100 \\
\hline II B & 2455 & 86 & 129 & 222 \\
\hline $12 \mathrm{~B}$ & 3073 & 49 & 88 & 302 \\
\hline 13 B & 1355 & 92 & 146 & 349 \\
\hline I4 B & 9729 & 40 & 52 & 75 \\
\hline $15 B$ & 4310 & 82 & 121 & 195 \\
\hline $16 B$ & 2045 & 148 & 264 & 563 \\
\hline $17 \mathrm{~B}$ & 10100 & 42 & 56 & 89 \\
\hline $18 \mathrm{~B}$ & 4200 & 85 & 125 & 203 \\
\hline $19 \mathrm{~B}$ & 1913 & 158 & 278 & 553 \\
\hline $20 \mathrm{~B}$ & $|I| 5 \mid$ & 41 & 54 & 83 \\
\hline $21 \mathrm{~B}$ & 4748 & 82 & 121 & 195 \\
\hline $22 B$ & 2231 & 149 & 266 & 557 \\
\hline $23 \mathrm{~B}$ & 8524 & 43 & 58 & 95 \\
\hline $24 \mathrm{~B}$ & 3438 & 85 & 128 & 205 \\
\hline $25 \mathrm{~B}$ & 1571 & 153 & 292 & 568 \\
\hline $26 \mathrm{~B}$ & 12345 & 42 & 55 & 80 \\
\hline 27 B & 5302 & 85 & 122 & 192 \\
\hline $28 \mathrm{~B}$ & 2444 & 152 & 259 & 558 \\
\hline $29 \mathrm{~B}$ & 5808 & 43 & 60 & 134 \\
\hline $30 \mathrm{~B}$ & 2896 & 83 & 121 & 198 \\
\hline $31 B$ & 1612 & III & 182 & 455 \\
\hline $32 \mathrm{~B}$ & 9552 & 42 & 56 & 84 \\
\hline $33 \mathrm{~B}$ & 3939 & 87 & 129 & 203 \\
\hline $34 \mathrm{~B}$ & 1778 & 160 & 278 & 558 \\
\hline $35 \mathrm{~B}$ & 11244 & 43 & 56 & 85 \\
\hline $36 \mathrm{~B}$ & 4626 & 87 & 130 & 209 \\
\hline 37 B & 2103 & 163 & 298 & 565 \\
\hline $38 \mathrm{~B}$ & 9801 & 43 & 56 & 88 \\
\hline $39 \mathrm{~B}$ & 4117 & 85 & 127 & 204 \\
\hline $40 \mathrm{~B}$ & 1903 & $|6|$ & 278 & 573 \\
\hline
\end{tabular}




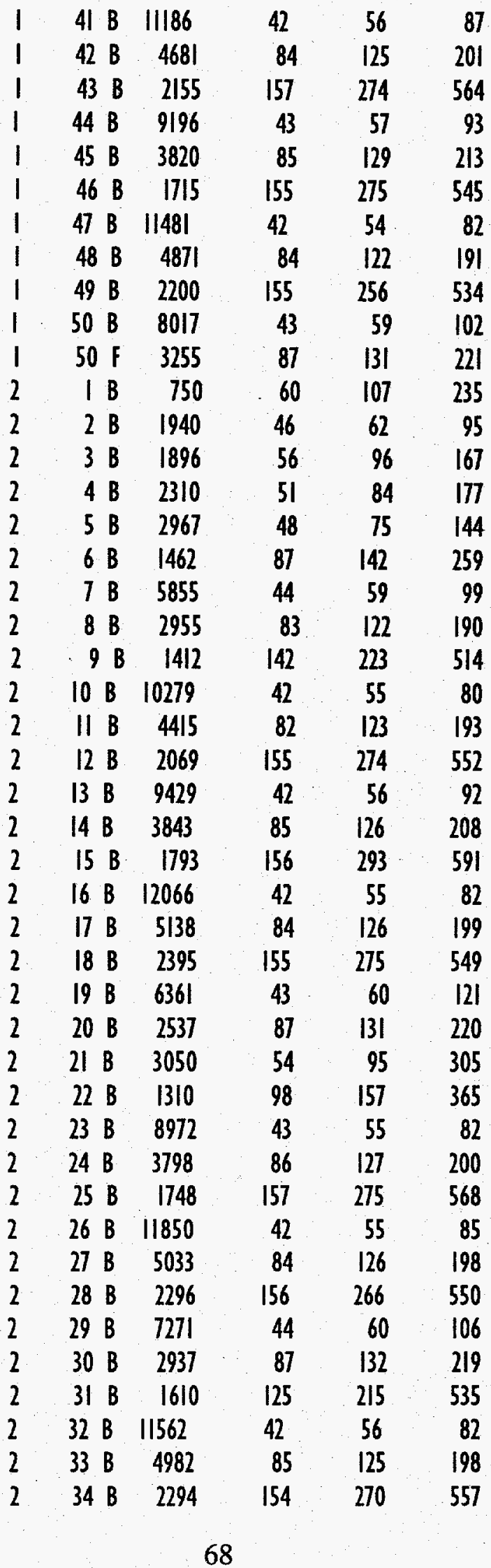




$\begin{array}{rrrrrrr}2 & 35 & \text { B } & 7550 & 43 & 58 & 101 \\ 2 & 36 & \text { B } & 3080 & 84 & 128 & 215 \\ 2 & 37 & \text { B } & 1328 & 155 & 284 & 551 \\ 2 & 38 & \text { B } & 11232 & 43 & 55 & 82 \\ 2 & 39 & \text { B } & 4835 & 85 & 126 & 202 \\ 2 & 40 & \text { B } & 2191 & 154 & 271 & 569 \\ 2 & 41 & \text { B } & 8773 & 43 & 57 & 95 \\ 2 & 42 & \text { B } & 3628 & 87 & 127 & 205 \\ 2 & 43 & \text { B } & 1625 & 159 & 293 & 560 \\ 2 & 44 & \text { B } & 11807 & 42 & 54 & 81 \\ 2 & 45 & \text { B } & 5151 & 85 & 126 & 196 \\ 2 & 46 & \text { B } & 2337 & 157 & 269 & 549 \\ 2 & 47 & \text { B } & 6755 & 44 & 60 & 114 \\ 2 & 48 & \text { B } & 2711 & 89 & 130 & 227 \\ 2 & 49 & \text { B } & 2433 & 61 & 144 & 395 \\ 2 & 50 & \text { B } & 4042 & 45 & 64 & 135 \\ 2 & 50 & \text { F } & 1990 & 87 & 130 & 213\end{array}$


SIMULATION : ...... I

BEFORE EXPOSURE

POPULATION : ...... 750
GESTATION PERIODS : . . . I

NUMBER OF FEMALES : . . . 375

ID SEX SIZE CUMSURY MTTD AGE NAT.TTD GROWTH WINTER LOCl:

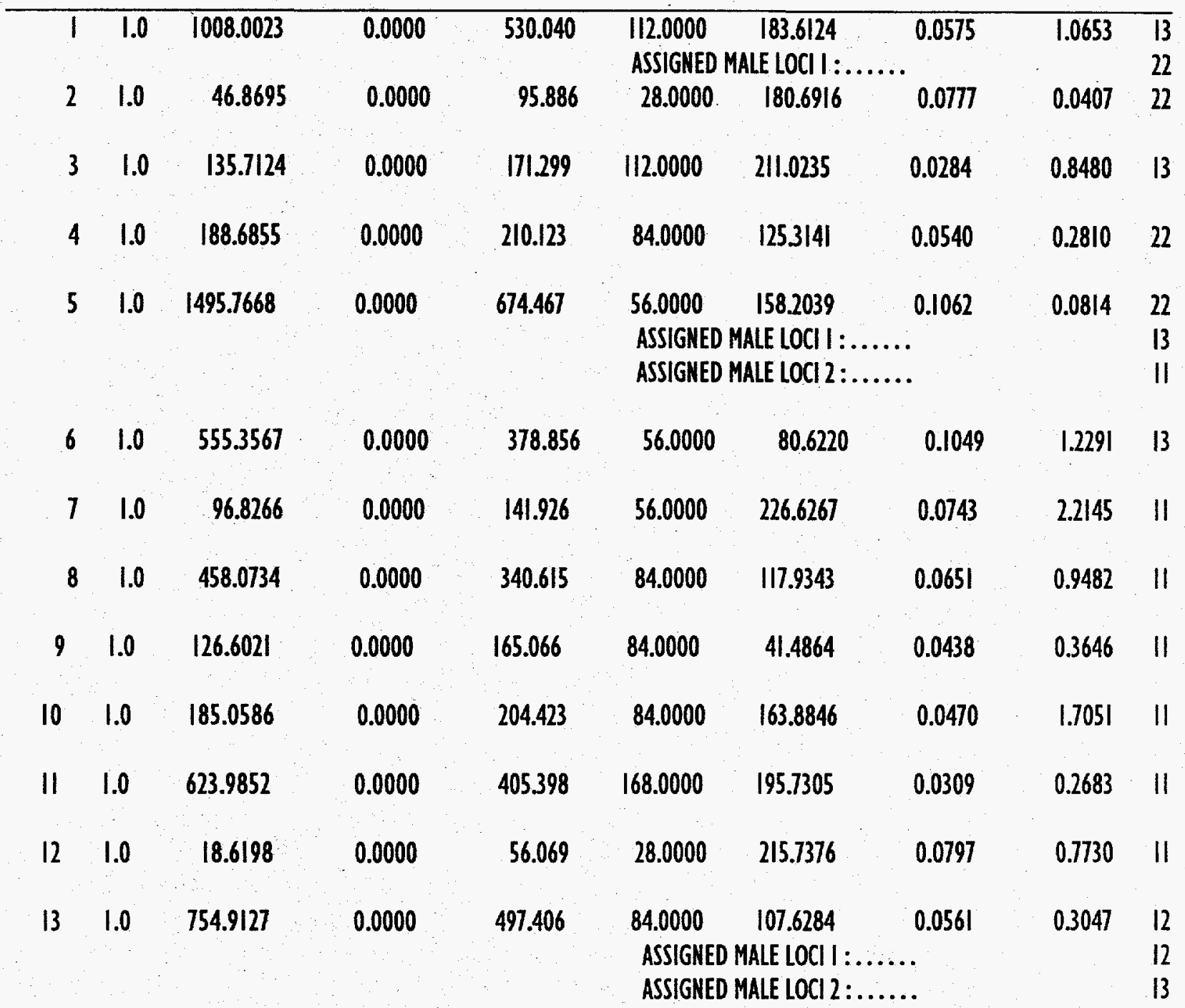


ID SEX SIZE CUMSURY MTTD AGE NAT.TTD GROWTH WINTER LOCI:

\begin{tabular}{lllllllllll}
\hline 739 & 0.0 & 33.9370 & 0.0000 & 54.636 & 56.0000 & 159.6893 & 0.0382 & 2.4642 & 22 \\
\hline 740 & 0.0 & 208.4662 & 0.0000 & 151.905 & 84.0000 & 120.8164 & 0.0516 & 0.1338 & 22 \\
\hline 741 & 0.0 & 52.5339 & 0.0000 & 69.884 & 28.0000 & 81.2287 & 0.0682 & 2.3726 & 22 \\
742 & 0.0 & 10.2058 & 0.0000 & 27.311 & 28.0000 & 100.2792 & 0.0654 & 3.3394 & 11 \\
743 & 0.0 & 215.7213 & 0.0000 & 151.999 & 56.0000 & 86.8918 & 0.0964 & 0.0585 & 13 \\
744 & 0.0 & 161.6347 & 0.0000 & 129.458 & 840.0000 & 107.2479 & 0.0205 & 0.4804 & 11 \\
745 & 0.0 & 78.0425 & 0.0000 & 87.338 & 56.0000 & 72.7606 & 0.0456 & 2.2230 & 22 \\
746 & 0.0 & 217.0473 & 0.0000 & 152.842 & 84.0000 & 80.6204 & 0.0647 & 0.0738 & 11 \\
747 & 0.0 & 14.6476 & 0.0000 & 33.476 & 28.0000 & 104.4454 & 0.0386 & 0.0910 & 11 \\
748 & 0.0 & 149.7896 & 0.0000 & 126.097 & 112.0000 & 47.6575 & 0.0398 & 1.1166 & 22 \\
\hline 749 & 0.0 & 19.8708 & 0.0000 & 39.750 & 28.0000 & 129.5409 & 0.1265 & 1.1478 & 11 \\
750 & 0.0 & 26.4521 & 0.0000 & 46.701 & 28.0000 & 96.7412 & 0.0502 & 1.2797 & 11
\end{tabular}




\section{SUMMARY OF ABOYE POPULATION}

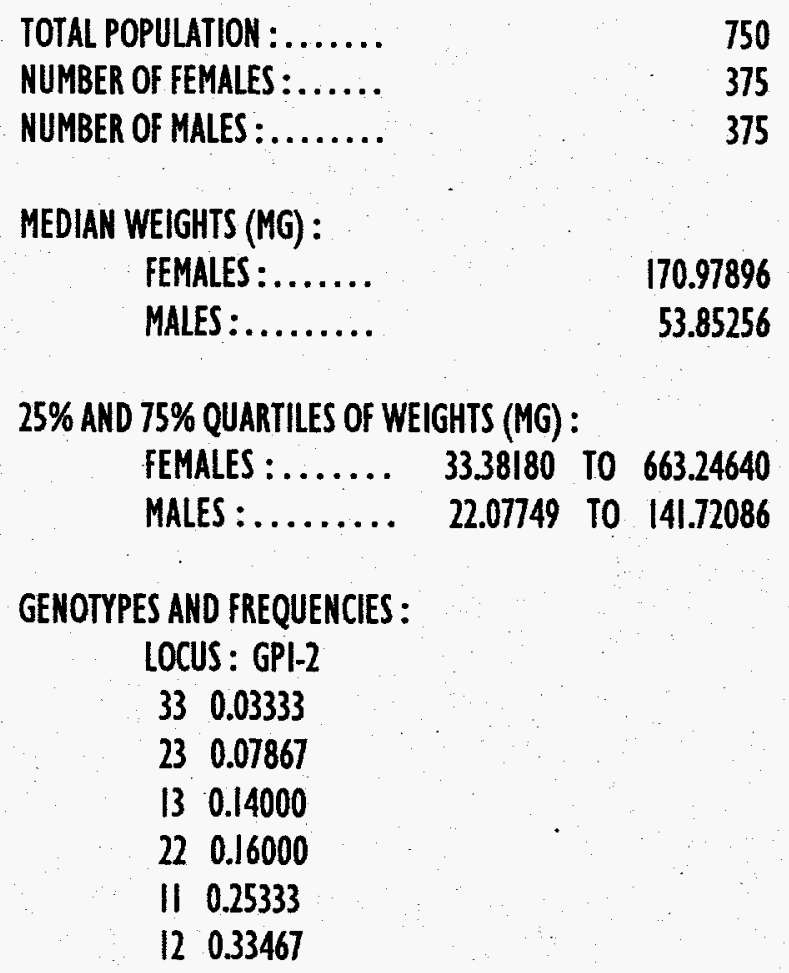

120.33467 


\begin{tabular}{|c|c|c|c|c|c|c|c|}
\hline & 751 & & & 53 & & & \\
\hline & 750 & 2 & 47 & 96 & & 18 & \\
\hline 1 & 750 & 31 & 136 & 171 & 112 & 21 & \\
\hline 1 & 750 & 41 & 189 & 210 & & 125 & \\
\hline 18 & 750 & 51 & 1496 & 14 & & Iro & \\
\hline & 7 & 11 & 555 & 19 & & & \\
\hline & 0 & 71 & 97 & & & 227 & \\
\hline 1 & 750 & 81 & 458 & $\|$ & 34 & $\|$ & \\
\hline 1 & 750 & 91 & 127 & 5 & & & \\
\hline 1 & 750 & 101 & 185 & 14 & 84 & 164 & \\
\hline 1 & 750 & 111 & 624 & 405 & 168 & 196 & \\
\hline 1 & 750 & 121 & 19 & 56 & 28 & 2 & \\
\hline I B & 750 & 131 & 229 & 231 & 56 & & \\
\hline IB & 750 & 141 & 755 & 497 & 84 & 108 & \\
\hline 18 & 750 & 151 & 445 & 69 & 140 & 69 & \\
\hline IB & 750 & 161 & 102 & 161 & 56 & 07 & \\
\hline IB & 750 & 171 & 130 & & 8 & 157 & \\
\hline IB & 750 & 181 & 1143 & 570 & 112 & 220 & \\
\hline I B & 750 & 191 & 175 & ? & & 148 & \\
\hline IB & 750 & 201 & 155 & 204 & 56 & 7 & \\
\hline IB & 750 & 211 & 115 & 54 & 8 & 4 & \\
\hline I B & 750 & 221 & 46 & 103 & 56 & 186 & \\
\hline I B & 750 & 231 & 35 & 89 & 84 & 139 & \\
\hline I B & 750 & 241 & 180 & 201 & & & \\
\hline 1 & - & 251 & & 132 & & 5 & \\
\hline
\end{tabular}

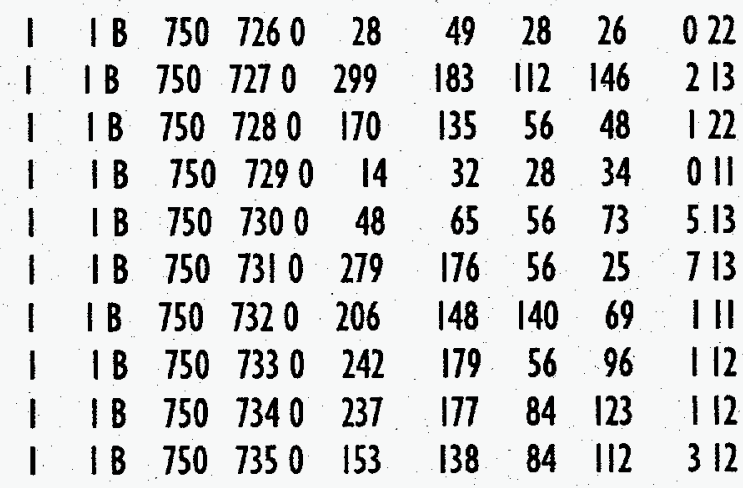




\begin{tabular}{|c|c|c|c|c|c|c|c|}
\hline I B & 750 & 7360 & 38 & 63 & 28 & 58 & 012 \\
\hline I B & 750 & 7370 & 47 & 71 & 56 & 27 & 112 \\
\hline I B & 750 & 7380 & 47 & 64 & 28 & 44 & 013 \\
\hline 18 & 750 & 7390 & 34 & 55 & 56 & 160 & 222 \\
\hline I B & 750 & 7400 & 208 & 152 & 84 & 121 & 022 \\
\hline I B & 750 & 7410 & 53 & 70 & 28 & 81 & 222 \\
\hline I B & 750 & 7420 & 10 & 27 & 28 & 100 & 311 \\
\hline I B & 750 & 7430. & 216 & 152 & 56 & 87 & 013 \\
\hline 18 & 750 & 7440 & 162 & 129 & 840 & 107 & 01 \\
\hline I B & 750 & 7450 & 78 & 87 & 56 & 73 & 222 \\
\hline I B & 750 & 7460 & 217 & 153 & 84 & 81 & 011 \\
\hline I B & 750 & 7470 & 15 & 33 & 28 & 104 & 011 \\
\hline I B & 750 & 7480 & 150 & 126 & 112 & 48 & 122 \\
\hline I B & 750 & 7490 & 20 & 40 & 28 & 130 & I \\
\hline I B & 750 & 7500 & 26 & $47^{\circ}$ & 28 & 97 & II \\
\hline
\end{tabular}

